\title{
The introduction of the SRF-II method to compare hypothesis of adaptive reuse for an iconic historical building
}

\author{
Francesca Abastante ${ }^{1}$, Salvatore Corrente ${ }^{2}$, Salvatore Greco ${ }^{2,3}$, Isabella M. Lami ${ }^{1}$, Beatrice \\ Mecca $^{1 *}$ \\ ${ }^{1}$ Department of Regional and Urban Studies and Planning (DIST), Politecnico di Torino, Viale Mattioli 39,10122 Torino,

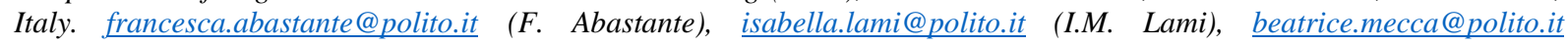 \\ *(corresponding author) (B. Mecca) \\ 2 Department of Economics and Business, University of Catania, Corso Italia, 55, 95129 Catania, Italy. \\ salvatore.corrente@unict.it (S.Corrente), salgreco@unict.it (S. Greco)
}

${ }^{3}$ University of Portsmouth, Portsmouth Business School, Centre of Operations Research and Logistics (CORL), Richmond Building, Portland Street, Portsmouth PO1 3DE, United Kingdom

\begin{abstract}
The paper shows how Multiple Criteria Decision Aiding (MCDA) tools can support the analyses of six hypotheses of adaptive reuse of an iconic historical building in Turin, Italy (called Stock Exchange) to identify the preferred alternative. In the last two years, the debate around the requalification of the building has been huge for several reasons: it is perceived as a "monument" by citizens; it shows architectural and typological values nationally recognized; it involves public and private interests. In this context, we tested the applicability of a recently proposed multicriteria decision making methodology to architecture field. This decision support approach is a conjunction of four MCDA methods, namely: Multiple Criteria Hierarchy Process (MCHP), permitting to consider structural relationships between criteria; ELECTRE III, considering three types of interaction effects between criteria (strengthening, weakening and antagonistic effects); the imprecise SRF method, supplying an easily understandable approach to collect information from the DM; and Stochastic Multicriteria Acceptability Analysis (SMAA), providing robust recommendation, in terms of rankings and relations of preference, indifference and incomparability between project alternatives, at each level of the hierarchy. We propose a modification of the SRF methodology, called SFR-II, to increase the reliability of the decision aid procedure, which could constitute a significant advance for the same SRF method.
\end{abstract}

Keywords: Multi-Criteria Decision Aiding (MCDA); decision support procedures; adaptive reuse; SRF-II method; architecture

\section{Introduction}

Transforming the many urban areas and buildings abandoned in the twentieth century is often complex and problematic, as it involves multiple objectives and stakeholders - e.g. owners, investors and public Decision Makers - who must all interact with each other. From an architectural standpoint, adaptive reuse has become a valuable approach for the sustainable rebirth of the city (Dewiyana et al. 2016, Permata et al., 2020), encouraging the reuse of existing and abandoned sites and buildings, avoiding the waste of energy and materials that new construction entails (Conejos et al 2014, Elefante 2007), preserving a portion of the urban landscape and delivering new social and economic profits (Dewiyana et al. 2016, Dyson et al 2016, Douglas 2006).

In this framework, it is important that decision analysis and decision-making be supported by methodologies where the required input information and the recommendations supplied as output are rigorous and accurate, but also as simple and understandable as possible. This calls for an appropriate "design" of the decision support procedure, or what has been termed "choice architecture for architecture choices" (Abastante et al. 2018). The literature provides a number of examples of real-case applications of adaptive reuse (Abastante et al. 2020; Lami 2020; Bottero et al. 2019; Della Spina, 2020; Oppio and Bottero, 2017; Oppio et al., 2017; Permata et al. 2020), where multicriteria approaches have proven to be an appropriate methodological framework for addressing the complexity of reuse problems. Accordingly, this paper tests the applicability of a multicriteria decision making methodology to architecture by investigating the most suitable design solution for the reuse of an iconic historical building.

The methodology adopted is an improvement of the one proposed by Corrente et al. (2017). It is composed of four Multiple Criteria Decision Aiding (MCDA) methods, namely: Multiple Criteria Hierarchy Process 
(MCHP) (Corrente et al. 2012, 2013), ELECTRE III (Roy and Bouyssou 1993), the imprecise Simos-RoyFigueira (SRF) method (Figueira and Roy 2002; Corrente et al. 2017) and Stochastic Multicriteria Acceptability Analysis (SMAA) (Lahdelma et al. 1998). In this mutlicriteria framework, the paper introduces the new "SRF-II method" which demands more natural questions for the DM. The methodological innovation was tested by applying it to a case study, whose alternative reuses were chosen in order to challenge the model, as will be illustrated below.

This decision support approach was chosen for several reasons: MCHP handles a large number of criteria, taking the hierarchical structure of the criteria used to evaluate alternatives into account; the ELECTRE III method considers three types of interaction between criteria (strengthening, weakening and antagonistic effects); the imprecise SRF-II method handles preference information provided by the DMs. The innovation we introduce in the latter method considers a "zero criterion", i,e., a threshold to which a null importance is assigned, thus making it easier for the DMs to elicit criteria weights. Our proposed improvement is of specific interest in the MCDA, because it collects more uniform information consisting only of numbers of blank cards between levels of criteria having equal importance, avoiding asking the DM the ratio between the weight of the most important criterion and the weight of the least important one, which is a very complex and cognitively requiring question for the DM. Lastly, the SMAA methodology provides robust recommendations by taking into account a plurality of vectors of parameters (e.g. criteria weights and coefficients representing interaction effects) compatible with the preferential information supplied by the DMs. These recommendations are expressed in terms of frequency of preference, indifference and incomparability between the project alternatives, at each level of the hierarchy.

The case study, the former Stock Exchange in Turin (Italy), is very promising, given that the unused building stock is currently an important issue in Italy and the rest of Europe, as it can be seen both as a problem and as a resource.

The Stock Exchange building has fuelled a complex debate over the past two years, since it is a historical monument for the people of Turin, presents architectural and typological values that should be preserved, and involves interests that are financial and economic, public and private. Given the many points of view voiced in this debate, we analyze six possible alternatives of transformation of the building using the new multimethodological framework to identify the solution preferred by the Decision Makers (DMs). Our aim was to find the alternative that best reflects the point of view of the property owner-the Turin Chamber of Commerce - and the funding entity - the Piedmont Regional Government. Not having the possibility to involve these two subjects directly, we decided to engage in the test of our methodology two consultants of the Politecnico di Torino project team, because they designed one of the six alternatives and thus acted as intermediaries with the real client, knowing its preferences and requests. In this sense, we assumed that they can act as DMs (and so will be defined throughout the paper), defining the set of preferences needed to apply the methodological framework.

The paper is organized as follows: section 2 provides a description of the methodological and theoretical framework, and section 3 investigates the concept of adaptive reuse. Section 4 describes the case study and the six project alternatives, section 5 illustrates the MCDA application, and section 6 presents its results. Conclusions and future developments are discussed in section 7.

\section{Methodological framework}

In MCDA (Greco et al. 2016), a set of alternatives $A=\{a, b, \ldots\}$ is evaluated on a set of aspects $G=$ $\left\{g_{1}, \ldots, g_{m}\right\}$, technically called criteria, to deal with a choice, ranking or sorting problem. In this paper we are interested in ranking problems in which alternatives must be partially or totally ordered from the best to the worst with the possibility that some will be ranked equally.

The only objective information that can be gathered about how the alternatives perform for the considered criteria is the dominance relation $D$ where $a D b$ if $a$ is at least as good as $b$ for all criteria and $a$ is better than $b$ for at least one. The objectivity of this relation is counterbalanced by its poverty, since in comparing a pair of alternatives $a$ and $b, a$ will quite often be better than $b$ on some criteria and $b$ will be better than $a$ on some others, so that neither $a D b$ nor $b D a$. For this reason, when comparing pairs of alternatives $a$ and $b$, the preferences with respect to the considered criteria of $a$ over $b$ must be aggregated and compared with the corresponding preferences of $b$ over $a$ to arrive at an overall comparison in terms of an outranking relation $S$ such that for each pair of alternatives $a$ and $b, a S b$ means that " $a$ is at least as good as $b$ ". On the basis of the comprehensive preference comparisons of all pairs of alternatives, a final recommendation on the considered problem can be made using some appropriate procedure (Roy 1990). Several MCDA methods have been introduced for this purpose. In this paper, we applied the robust and hierarchical ELECTRE III method (Corrente et al. 2017), being the conjunction of four methods one of which, the SRF, is improved giving rise to the SRF-II method. The four methods composing the applied methodological framework will be presented in the following sections. 


\subsection{Multiple Criteria Hierarchy Process}

In almost all real-world problems, the evaluation criteria are not at the same level, but are structured hierarchically. It is thus possible to define a root criterion (i.e., the objective of the decision problem, corresponding to an overall evaluation of considered alternatives), some macro-criteria and other criteria descending from them. For a decision problem involving the adaptive reuse of a historical building as is the case for this paper, the macrocriteria could consist of Technical aspects, Economic aspects, and Reuse and Social aspects. Each of these macrocriteria can be then detailed with specific subcriteria, so that: intended use innovation and work duration can be subcriteria of Technical aspects, maintenance cost, net present value and payback period can be subcriteria of Economic aspects, impact on architectural value and physical impact can be subcriteria of Reuse aspects, and human resources can be a subcriterion of Social aspects.

The MCHP (Corrente et al. 2012, 2013) was introduced to take the hierarchy of criteria explicitly into account, in our case by defining an outranking relation $S_{r}$ for each node $g_{r}$ corresponding to some macrocriterion or subcriterion or also at the root node, in the same hierarchy, so that $a S_{r} b$ means that $a$ is at least as good as $b$ on $g_{r}$. Finer recommendations on the problem at hand can thus be obtained by considering specific aspects relating to each individual macro-criterion and sub-criterion at a time, in addition to the overall evaluation stemming from conjoint consideration of all criteria simultaneously.

From a formal standpoint, $g_{o}$ is the root criterion; $g_{r}$ is a generic criterion in the hierarchy of criteria; $G$ is the set of all criteria in the hierarchy; $I_{G}$ is the set of the indices of all criteria in the hierarchy; $G_{E L} \subseteq G$ is the set composed of all elementary criteria, i.e., the criteria at the bottom of the hierarchy (which thus cannot be further detailed with lower level sub-criteria) and on which the alternatives are evaluated; $E L \subseteq I_{G}$ is the set of the indices of all elementary criteria; $g_{t}$, with $t \in E L$, denotes an elementary criterion, while the term nonelementary criterion is used to mean a criterion $g_{r}$ such that $r \in I_{G} \backslash E L$; lastly, $E\left(g_{r}\right) \subseteq E L$ is the set of the indices of all elementary criteria descending from the non-elementary criterion $g_{r}$.

\subsection{The hierarchical ELECTRE III method with interactions between criteria}

Quite often, the criteria considered in decision problems are not mutually preferentially independent (Keeney and Raiffa 1976; Wakker 1989), but present a certain type of interaction. In the case of outranking methods and, in particular, for the ELECTRE methods we apply here, we distinguish between mutual-strengthening effect, mutual-weakening effect and antagonistic effects (Figueira et al. 2009). Elementary criteria $g_{t_{1}}$ and $g_{t_{2}}$ present a mutual-strengthening effect if the importance given to them together is greater than the sum of the importance given to them singularly; $g_{t_{1}}$ and $g_{t_{2}}$ present a mutual-weakening effect, if the importance given to them together is lower than the sum of the importance given to them singularly; lastly, $g_{t_{1}}$ exercises an antagonistic effect over $g_{t_{2}}$, if the importance of $g_{t_{1}}$, which is in favor of the outranking of a certain alternative $a$ over another alternative $b$, is lowered by the presence of $g_{t_{2}}$, which is against the same outranking.

The ELECTRE III method belongs to the ELECTRE family (Figueira et al. 2013; Govindan and Jepsen 2016). All ELECTRE methods are based on the construction of an outranking relation $S$ that is fulfilled by two alternatives $a$ and $b$, formally $a S b$, if a concordance and a non-discordance test are verified. The concordance test is verified if the majority of criteria is in favor of the outranking of $a$ over $b$, while the nondiscordance test is verified if none of the remaining criteria is too strongly opposed to such an outranking. In the hierarchical ELECTRE III method with interactions, the concordance and discordance tests are dealt simultaneously by building a credibility index $\sigma_{r}(a, b)$ for each ordered pair of alternatives $(a, b) \in A \times A$, and for each non-elementary criterion $g_{r}$ by means of the following steps:

1) For each elementary criterion $g_{t}, \mathrm{t} \in E\left(g_{r}\right)$, a partial concordance index $\varphi_{t}(a, b)$ and a partial discordance index $d_{t}(a, b)$ are computed:

$$
\varphi_{t}(a, b)=\left\{\begin{array}{cccc}
1 & \text { if } & g_{t}(b)-g_{t}(a) \leq q_{t} & \left(a S_{t} b\right)^{1} \\
\frac{p_{t}-\left[g_{t}(b)-g_{t}(a)\right]}{p_{t}-q_{t}} & \text { if } & q_{t}<g_{t}(b)-g_{t}(a)<p_{t} & \left(b Q_{t} a\right) \\
0 & \text { if } & g_{t}(b)-g_{t}(a) \geq p_{t} & \left(b P_{t} a\right)
\end{array}\right.
$$

\footnotetext{
${ }^{1} a S_{t} b$ means that $a$ is at least as good as $b$ on $g_{t} ; b Q_{t} a$ means that $b$ is weakly preferred (that is, preferred with some hesitation) to $a$ on $g_{t}$, while $b P_{t} a$ means that $b$ is strictly preferred to $a$ on $g_{t}$.
} 


$$
d_{t}(a, b)=\left\{\begin{array}{ccc}
1 & \text { if } & g_{t}(b)-g_{t}(a) \geq v_{t} \\
\frac{\left[g_{t}(b)-g_{t}(a)\right]-p_{t}}{v_{t}-p_{t}} & \text { if } & p_{t}<g_{t}(b)-g_{t}(a)<v_{t} \\
0 & \text { if } & g_{t}(b)-g_{t}(a) \leq p_{t}
\end{array}\right.
$$

where $q_{t}, p_{t}$ and $v_{t}$ are the indifference, preference and veto thresholds attached to $g_{t}$. In particular, $q_{t}$ is the maximum difference between the performances of two alternatives on $g_{t}$, compatible with their indifference on the considered elementary criterion; $p_{t}$ is the minimum difference between the performances of two alternatives on $g_{t}$, compatible with the preference of the best performing over the worst performing alternative; lastly, $v_{t}$ is the minimum difference between the performances of two alternatives on $g_{t}$, incompatible with the outranking of one over the other. This means that, if $g_{t}(b)-g_{t}(a) \geq v_{t}$, then $a$ cannot outrank $b$ on any macro-criterion $g_{r}$ from which $g_{t}$ descends, independently of their comparison on the other criteria (for more details see Roy et al. 2014).

Both $\varphi_{t}(a, b)$ and $d_{t}(a, b)$ belong to the interval $[0,1]$ but they are interpreted differently: on the one hand, $\varphi_{t}(a, b)$ measures how much $g_{t}$ is in favor of the outranking of $a$ over $b$. The higher $\varphi_{t}(a, b)$, the more $g_{t}$ is in favor of the outranking. On the other hand, $d_{t}(a, b)$ measures how much $g_{t}$ is against the outranking of $a$ over $b$. The higher $d_{t}(a, b)$, the more $g_{t}$ is against the outranking. More precisely, with respect to $\varphi_{t}(a, b)$,

- if $g_{t}(b)-g_{t}(a)$ is not greater than the indifference threshold $q_{t}$, then $g_{t}$ is fully in concordance with the outranking of $a$ over $b$, so that $\varphi_{t}(a, b)$ attains its maximum value of 1 ;

- if $g_{t}(b)-g_{t}(a)$ is not smaller than the preference threshold $p_{t}$, then $g_{t}$ is definitely not in concordance with the outranking of $a$ over $b$, so that $\varphi_{t}(a, b)$ attains its minimum value of 0 ;

- in all other cases, i.e., when $g_{t}(b)-g_{t}(a)$ is greater than the indifference threshold $q_{t}$ and smaller than the preference threshold $p_{t}$, then $g_{t}$ is partially in concordance with the outranking of $a$ over $b$, so that $\varphi_{t}(a, b)$ takes a value between 0 and 1 , decreasing linearly from $\varphi_{t}(a, b)=1$ (for $g_{t}(b)-$ $\left.g_{t}(a)=q_{t}\right)$ to $\varphi_{t}(a, b)=0\left(\right.$ for $\left.g_{t}(b)-g_{t}(a)=p_{t}\right)$.

With respect to $d_{t}(a, b)$,

- if $g_{t}(b)-g_{t}(a)$ is not smaller than the veto threshold $v_{t}$, then $g_{t}$ is definitely in discordance with the outranking of $a$ over $b$, so that $d_{t}(a, b)$ attains its maximum value of 1 ;

- if $g_{t}(b)-g_{t}(a)$ is not greater than the preference threshold $p_{t}$, then $g_{t}$ is definitely not in discordance with the outranking of $a$ over $b$, so that $d_{t}(a, b)$ attains its minimum value of 0 ;

- in all other cases, i.e., when $g_{t}(b)-g_{t}(a)$ is greater than the preference threshold $p_{t}$, and smaller than the veto threshold $v_{t}$, then $g_{t}$ is partially in discordance with the outranking of $a$ over $b$, so that $d_{t}(a, b)$ takes a value between 0 and 1 , increasing linearly from $d_{t}(a, b)=0$ (for $\left(g_{t}(b)-g_{t}(a)=\right.$ $p_{t}$ ) to $d_{t}(a, b)=1$ (for $\left.g_{t}(b)-g_{t}(a)=v_{t}\right)$.

2) After defining the importance $w_{t}$ of the elementary criteria $g_{t}$, the coefficients $w_{t_{1} t_{2}}$ representing the mutual-weakening and mutual-strengthening effects between $g_{t_{1}}$ and $g_{t_{2}}$ and the coefficient $w_{t_{1} t_{2}}^{\prime}$ representing the antagonistic effect exercised by criterion $g_{t_{2}}$ over $g_{t_{1}}$, a partial concordance index $C_{r}(a, b)$ is computed for each non-elementary criterion $g_{r}$ and for each ordered-pair of alternatives $(a, b) \in A \times A$ :

$$
\begin{aligned}
C_{r}(a, b)=\frac{1}{W_{r}(a, b)}\left[\sum_{t_{1} \in \bar{C}(b P a) \cap E\left(g_{r}\right)} w_{t_{1}} \varphi_{t_{1}}(a, b)\right. \\
+\sum_{t_{1}, t_{2} \in \bar{C}(b P a) \cap E\left(g_{r}\right)} w_{t_{1} t_{2}} \min \left(\varphi_{t_{1}}(a, b), \varphi_{t_{2}}(a, b)\right) \\
\left.-\sum_{t_{1} \in \bar{C}(b P a) \cap E\left(g_{r}\right)} w_{t_{2} t_{2}}^{\prime} \min \left(\varphi_{t_{1}}(a, b), \varphi_{t_{2}}(b, a)\right)\right]
\end{aligned}
$$

where $C(b H a)$ denotes the set of elementary criteria $g_{t}$ such that $b H_{t} a, H \in\{S, Q, P\}, \bar{C}(b H a)$ represents the complement of $C(b H a)$ and 


$$
\begin{gathered}
W_{r}(a, b)=\left[\sum_{t_{1} \in \bar{C}(b P a) \cap E\left(g_{r}\right)} w_{t_{1}}+\sum_{t_{1}, t_{2} \in \bar{C}(b P a) \cap E\left(g_{r}\right)} w_{t_{1} t_{2}} \min \left(\varphi_{t_{1}}(a, b), \varphi_{t_{2}}(a, b)\right)\right. \\
\left.-\sum_{\substack{t_{1} \in \bar{C}(b P a) \cap E\left(g_{r}\right) \\
t_{2} \in C(b P a) \cap E\left(g_{r}\right)}} w_{t_{1} t_{2}}^{\prime} \min \left(\varphi_{t_{1}}(a, b), \varphi_{t_{2}}(b, a)\right)\right] .
\end{gathered}
$$

$C_{r}(a, b)$ is a value belonging to the interval $[0,1]$ and represents how much the elementary criteria descending from $g_{r}$ are in favor of the outranking of $a$ over $b$. The higher $C_{r}(a, b)$, the more elementary criteria descending from $g_{r}$ are in favor of this outranking.

3) For each ordered pair of alternatives $(a, b) \in A \times A$ and for each non-elementary criterion $g_{r}$, the credibility index is thus computed as follows:

$$
\sigma_{r}(a, b)=C_{r}(a, b) \prod_{\left\{t \in E\left(g_{r}\right): d_{t}(a, b)>C_{r}(a, b)\right\}} \frac{1-d_{t}(a, b)}{1-C_{r}(a, b)} .
$$

$\sigma_{r}(a, b)$ is the credibility of the outranking of $a$ over $b$ and is equal to the value $C_{r}(a, b)$ reduced if some elementary criteria descending from $E\left(g_{r}\right)$ oppose this outranking. In particular, $\sigma_{r}(a, b)=$ $C_{r}(a, b)$ if none of the elementary criteria in $g_{r}$ opposes the outranking of $a$ over $b$ and $\sigma_{r}(a, b)=0$ if at least one of the elementary criteria in $E\left(g_{r}\right)$ strongly opposes the outranking.

4) On the basis of the credibility indices $\sigma_{r}(a, b)$ computed in the previous step, two complete preorders (i.e., a complete ranking admitting ex-aequo) of the alternatives are obtained for each nonelementary criterion $g_{r}$ by means of two specific procedures called ascending and descending distillation and, lastly, a partial pre-order (i.e., a ranking admitting ex-aequo as well as incomparability) of the same alternatives is computed as the intersection of the complete pre-orders found above. In particular, with respect to a criterion $g_{r}$ and a pair of alternatives $a$ and $b$, we have - a preference relation, denoted by $a P_{r} b$, if $a S_{r} b$ and $\operatorname{not}\left(b S_{r} a\right)$ (i.e., $a$ outranks $b$, but $b$ does not outrank $a$ with respect to $g_{r}$ ),

- an indifference relation, denoted by $a I_{r} b$, if $a S_{r} b$ and $b S_{r} a$ (i.e., $a$ outranks $b$ and $b$ outranks $a$ with respect to $g_{r}$ ), and

- an incomparability relation, denoted by $a R_{r} b$, if $\operatorname{not}\left(a S_{r} b\right)$ and $\operatorname{not}\left(b S_{r} a\right)$ (i.e., $a$ does not outrank $b$ and $b$ does not outrank $a$ with respect to $g_{r}$ ) (for more details see Corrente et al. 2017).

\subsection{The hierarchical and imprecise Simos-Roy-Figueira (SRF) method}

As explained in the previous section, applying the hierarchical ELECTRE III method with interaction between criteria requires that several parameters be known: one weight $w_{t}$ for each elementary criterion $g_{t}$, one coefficient $w_{t_{1} t_{2}}$ for each pair of elementary criteria $g_{t_{1}}$ and $g_{t_{2}}$ for which there is a mutualstrengthening effect or a mutual-weakening effect, and one coefficient $w_{t_{1} t_{2}}^{\prime}$ for each ordered pair of criteria $g_{t_{1}}$ and $g_{t_{2}}$ such that $g_{t_{2}}$ exercises an antagonistic effect over $g_{t_{1}}$. However, asking the DM to provide all these technical parameters directly is meaningless since it involves a considerable cognitive effort on her part and the result obtained would not be reliable. To determine the weights of the elementary criteria, Corrente et al. (2017) proposed a modification of the SRF method (Figueira and Roy 2002) considering a hierarchy of criteria and imprecise preference information from the DM. For each nonelementary criterion $g_{r}$, the imprecise SRF method is applied to the set of criteria $\left\{g_{(r, 1)}, \ldots g_{(r, n(r))}\right\}$ composed of the criteria descending from $g_{r}$ and sited at the level immediately below it. The SRF elicitation procedure proceeds by asking the DM to:

1. Rank order the criteria in $\left\{g_{(r, 1)}, \ldots g_{(r, n(r))}\right\}$ from the least important to the most important with the possibility of some ex-aequo between them;

2. Put some blank cards (an exact number $e_{r}$ or an interval of possible values $\left[e_{r}^{l}, e_{r}^{u}\right]$ ) between two successive subsets of criteria to increase the difference of importance between the criteria in these sets';

3. Define the ratio (an exact value $z$ or an interval of possible values $\left[z^{l}, z^{u}\right]$ ) of the weight of the most important criteria to the weight of the least important ones.

\footnotetext{
${ }^{2}$ It should be pointed out that no blank cards between two successive subsets of criteria does not mean that the criteria in these sets have the same importance, but that the difference of importance between them is minimal.
} 
For the basic case in which only an exact number of cards is given between two successive subsets of criteria and an exact value $\mathrm{z}$ is given to the ratio of the weights of the most important and least important criteria, the non-normalized weight for criteria in the $s$-th level of $q$ levels with increasing importance is given by (Corrente et al. 2016)

$$
w_{s}=\frac{\sum_{r=1}^{s-1}\left(e_{r}+1\right)(z-1)}{\sum_{r=1}^{q-1}\left(e_{r}+1\right)}+1 .
$$

As for the possible interactions between criteria as well as for the antagonistic effect between them, the DM is only asked to indicate the type of interaction, that is, she has only to say if she believes that there is a mutual-weakening or a mutual-strengthening effect between two elementary criteria or that there is an antagonistic effect exercised by one elementary criterion over another.

\subsection{The new SRF-II method}

Regarding the last question asked to the DM in the SRF elicitation procedure, namely the elicitation of a ratio $\mathrm{z}$ of the weight of the most important criteria to the weight of the least important ones, we propose an improvement to assist the DM in gaining a better understanding of the required information and, consequently, in order to produce a more consistent and solid elicitation of the weights assigned to criteria. Indeed, while in step 2. the DM is asked to indicate the difference of importance between criteria placed in consecutive subsets, in step 3. the DM is asked to indicate the ratio (not the difference) between the importance of criteria sited in the extreme subsets. In other words, the DM is asked to specify how many times the most important criteria are more important than the least important ones. Providing such a preference can be problematic for the DM because she is asked to define a ratio $\mathrm{z}$ without any reference parameters, and above all without the help of cards, which are a means of visually and concretely explicating abstract subjective information. For this reason, we have here replaced step 3. with the following one, introducing the new concept of SFR-II:

4. Define the number of blank cards (an exact value or an interval of possible values) that should be included between a zero-level of importance, which we will call the "zero criterion", and the least important criterion. Fig. 1 provides the scheme of the new process replacing the definition of the ratio $\mathrm{z}$ in the SRF method.

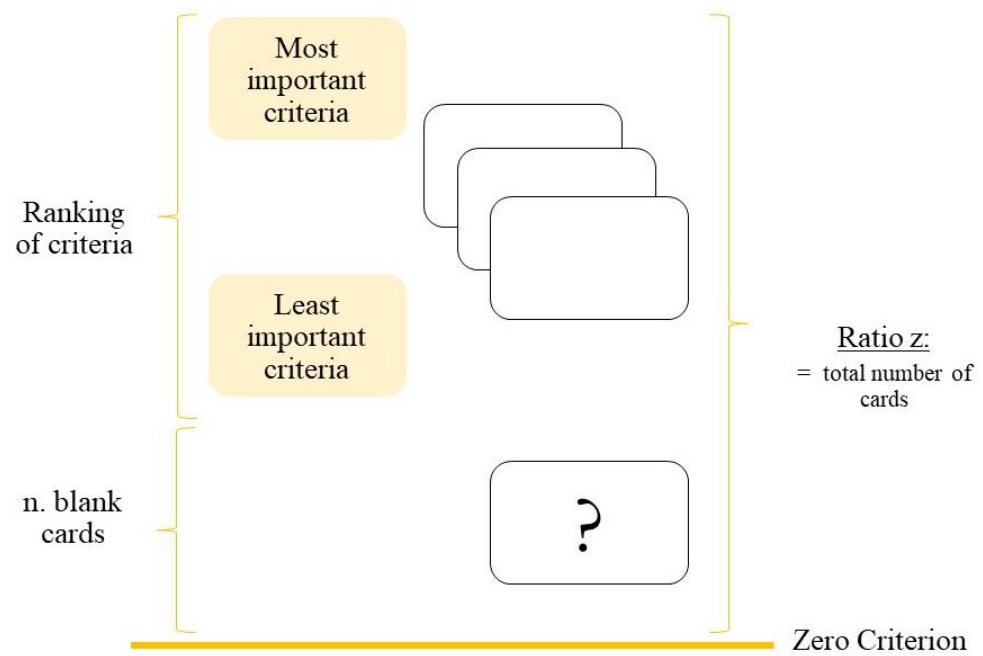

Fig. 1 SRF-II procedure for defining ratio $\mathrm{z}$

A few words are in order regarding the reasons for asking for the $\mathrm{z}$ value and the number of blank cards between the "zero criterion" and the least important criterion. Figueira and Roy (2002) considers a decision problem with four criteria ranked in increasing order of importance, let us say $g_{1}, g_{2}, g_{3}$ and $g_{4}$. Moreover, it is supposed that the DM considers the same difference of importance between each criterion and the following one. A first possible representation of this information in terms of cards consists of not inserting any blank card between the cards representing each criterion and giving each criterion $g_{r}, r=$ $1,2,3,4$, a weight equal to the number of cards between the card corresponding to the least important criterion and the card corresponding to the same criterion $g_{r}$, so that weights $w_{1}=1, w_{2}=2, w_{3}=3$ and $w_{4}=4$ are given to $g_{1}, g_{2}, g_{3}$ and $g_{4}$, respectively. This is the procedure proposed by Simos (1990), which assigns, implicitly, a value $z=\frac{w_{4}}{w_{1}}=4$ to the ratio between the weight of the most important criterion and the weight of the least important one. Note, however, that the value of $z$ is assigned 
automatically and without taking into account the opinion of the DM, who could prefer weights $w_{1}=$ $3, w_{2}=4, w_{3}=5$ and $w_{4}=6$ or $w_{1}=6, w_{2}=7, w_{3}=8$ and $w_{4}=9$ that cannot be obtained with the Simos procedure. For this reason, Figueira and Roy (2002) proposed asking the DM to supply the value of $z$. In this way, in the above example, with the same arrangement of cards and blank cards (in fact, in the considered example, only cards),

if the DM indicates $z=4$, we obtain weights $w_{1}=1, w_{2}=2, w_{3}=3$ and $w_{4}=4$,

if the DM indicates $z=2$, we obtain weights $w_{1}=3, w_{2}=4, w_{3}=5$ and $w_{4}=6$,

if the DM indicates $z=\frac{3}{2}$, we obtain weights $w_{1}=6, w_{2}=7, w_{3}=8$ and $w_{4}=9$.

Note that the same weights obtained with $z=2$ could be assessed with the information that there are two blank cards between the "zero criterion" and the least important criterion $g_{1}$. Similarly, five blank cards between the "zero criterion" and $g_{1}$ are equivalent to $z=\frac{3}{2}$ and give the same weights. In this example, denoting by $e_{0}$ the number of blank cards between the "zero criterion" and $g_{1}$, the following relation holds between $z$ and $e_{0}: z=\frac{e_{0}+4}{e_{0}+1}$. Moreover, in general, in terms of $e_{0}$ rather than $z$, the non-normalized weight for criteria in the $s$-th level of $q$ levels with increasing importance is given by

$$
w_{s}=\sum_{r=0}^{s-1}\left(e_{r}+1\right)
$$

Consequently, for the general case, the following relation obtains between the values of $z$ and $e_{0}$ :

$$
z=\frac{\sum_{r=1}^{q-1}\left(e_{r}+1\right)+e_{0}+1}{e_{0}+1}
$$

The input of the new proposal come from past experience of the authors in applying the SRF method to get the weights of criteria to be used in ELECTRE III methods. Indeed, many times and also in the case study we will present in this paper, the DMs found themselves uncomfortable in providing the $\mathrm{z}$ value since it was not clear for them which is the meaning of the "ratio" between the weight of the most important criterion and the weight of the least important one. For such a reason, in interacting with the DMs involved in the case study presented in the paper, we adopted the SRF-II method replacing, therefore, step 3. by step 4. The DMs who were asked before to apply the SRF method providing, therefore, the $\mathrm{z}$ value, really appreciated the introduction of the zero criterion and the possibility to give a preference information coherent with the preference information asked in step 2. of the SRF method. From this perspective we believe that our case study proves that reformulating the SRF method in terms of $e_{0}$ is a convenient and fruitful innovation for the entire methodology that can be applied advantageously in decision problems in any domain, not only in the domains of architecture and urban and territorial planning.

\subsection{Stochastic Multicriteria Acceptability Analysis}

In general, more than one vector of parameters (weights of criteria and coefficients representing mutualweakening, mutual-strengthening and antagonistic effects) could be compatible with the preference information provided by the DM. For this reason, providing a final recommendation on the problem at hand by using only one of these vectors is meaningless and arbitrary to some extent. The Stochastic Multicriteria Acceptability Analysis (SMAA) avoids such a choice by considering all compatible vectors of parameters and, therefore, provides robust recommendations on the considered problem. In particular, applying the SMAA methodology to the hierarchical ELECTRE III method gives information in statistical terms (for more details see Corrente et al. 2017) providing:

- for each non-elementary criterion $g_{r}$ and for each ordered pair of alternatives $(a, b) \in A \times A$, the frequency of preference $\left(P_{r}(a, b)\right)$, indifference $\left(I_{r}(a, b)\right)$ and incomparability $\left(R_{r}(a, b)\right)$ between $a$ and $b$ on $g_{r}$;

for each non-elementary criterion $g_{r}$, the most frequent partial pre-orders and the barycenters of the vectors of parameters for which these partial pre-orders are obtained.

\subsection{A flow-chart of the applied methodology}

In this section, we shall briefly summarize the methodology we are applying to the case study by means of a flow-chart which steps are shown in Fig. 2 and described in the following:

Step 0: Structure the criteria in a hierarchical way following the MCHP principles highlighting macrocriteria at the different levels and elementary criteria at the basis of the hierarchy. The performances of the alternatives at hand have to be provided with respect to the elementary criteria only; 
Step 1.1: The DM is invited to introduce the indifference, preference and veto thresholds for the elementary criteria on which she deserves to do. As it will be evident in the application of the methodology to the case study, the DM is not obliged to provide the thresholds for all elementary criteria. Such thresholds can be provided exactly or by means of an interval of variation;

Step 1.2: The DM is invited to provide information on the eventual presence of mutual-weakening, mutual-strengthening and antagonistic effects between pairs of elementary criteria. As in Step 1.1, the $\mathrm{DM}$ is not forced to provide this type of preference information. She can provide if she aims to. Moreover, it is important to underline that the DM has not to provide exact values for such effects but she has only to state their eventual presence;

Step 1.3: The DM has to apply the new SRF-II method at all levels of the hierarchy. This means that, for each non-elementary criterion $g_{r}$, she is invited to apply the SRF-II method to the set of criteria $\left\{g_{(r, 1)}, \ldots, g_{(r, 2)}\right\}$ composed of the criteria descending from $g_{r}$ and placed at the level immediately below it;

Step 2: All the preferences provided by the DM in steps 1.2 and 1.3 are converted into linear inequalities and, then, a particular programming problem has to be solved to check if it does exists at least one vector of parameters compatible with such information (for more details, see Corrente et al. 2017). If it does exist at least one of these vectors, go to step 3 below, otherwise, check for the cause of such an infeasibility (step 2.1) by means of one of the methods introduced by Mousseau et al. (2003);

Step 3: Sample several vectors of parameters by using a sampling procedure. In this case, since the inequalities translating the preferences of the DM define a convex set of vectors of parameters, the HitAnd-Run method (Smith 1984; Tervonen et al. 2013) can be applied;

Step 4: For each sampled vector of parameters and for each non-elementary criterion, we apply the ELECTRE-III method to get a partial preorder of the alternatives at hand;

Step 5: Apply the SMAA to get the following information in statistical terms for each non-elementary criterion $g_{r}$ :

- $\quad$ Frequency of preference, indifference and incomparability on $g_{r}$ for each ordered pair of alternatives $(a, b) \in A \times A$;

- $\quad$ Most frequent partial pre-orders with respect to $g_{r}$ and barycenter of the vectors of parameters for which the partial pre-orders are obtained.

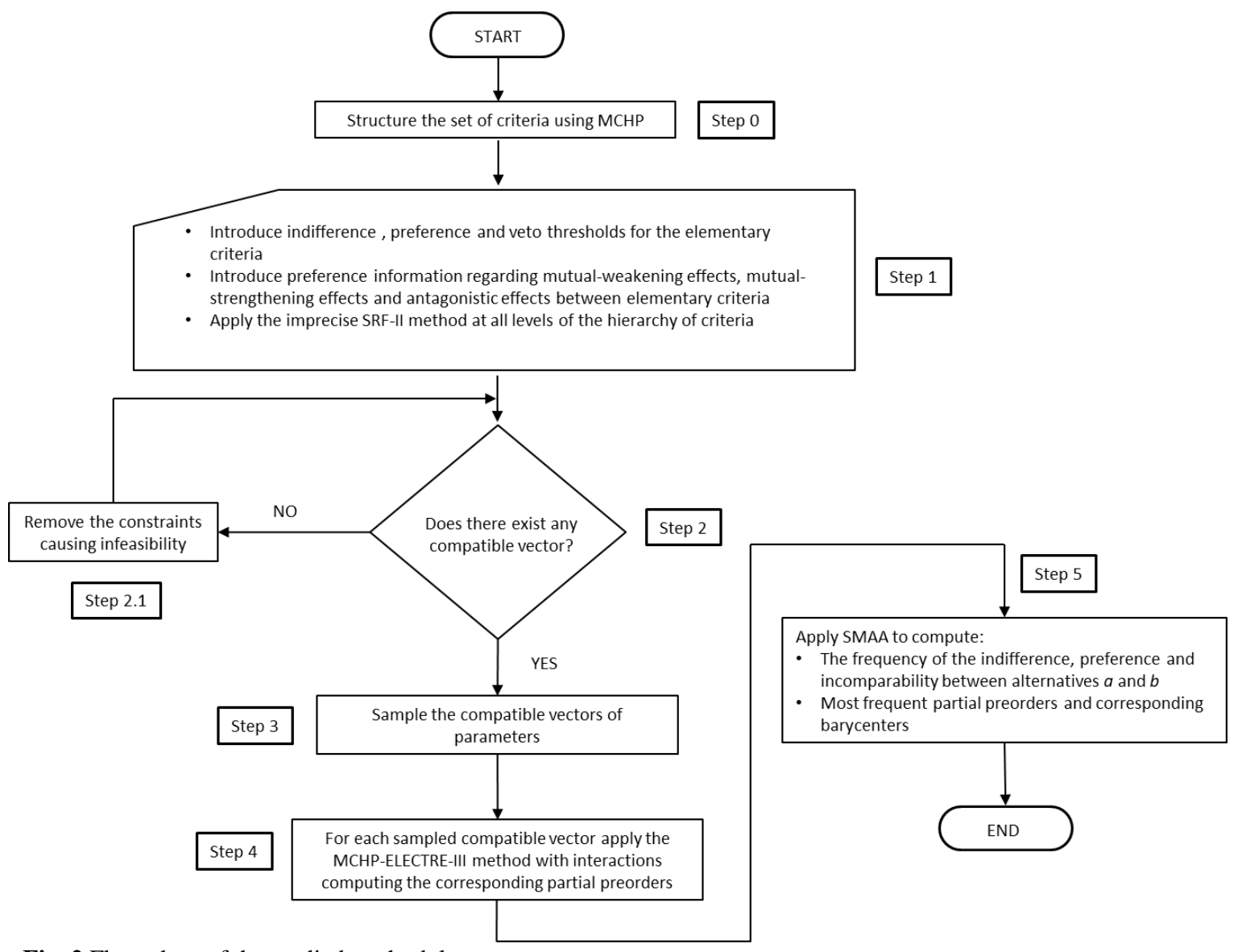

Fig. 2 Flow-chart of the applied methodology 


\section{The concept of adaptive reuse}

With an increasing number of abandoned buildings, adaptive reuse is a valuable means of exploiting this potential asset. In the $20^{\text {th }}$ century, adaptive reuse came to be regarded as a creative discipline for preserving the cultural heritage and for tackling the huge social, technological and environmental changes (Plevoets and Van Cleempoel 2013), assuming that buildings, areas, districts and sites are not static entities designed simply for one use during their life cycle.

Adaptive reuse emerged first as a practice, then as a theory, of introducing a new content in an existing container (i.e., a building, infrastructure or area), paying particular attention to society's needs and following the principle of maximum conservation and minimal transformation (Robiglio 2016). Furthermore, this practice should not involve extensive work and changes to existing buildings, but sees heritage as an opportunity to turn disused buildings into new items with new purposes (Bullen and Love 2011a, Permata et al 2020). Buildings become obsolete, but they continue to have a symbolic value and meaning for the place or for the community, and are thus "memory carriers" (Fiorani et al., 2017). Each building, area or site that is part of the architectural heritage has unique historical and cultural characteristics that must be preserved through sustainable solutions. Adaptive reuse is in line with the concept of sustainable architecture (Permata et al 2020); indeed, it can be seen as the nexus between heritage conservation and the promotion of sustainability, following the circular economy paradigm (Foster, 2020). The European Parliament (2016) has defined the circular economy as "an economic model based inter alia on sharing, leasing, reuse, repair, refurbishment and recycling, in an (almost) closed loop, which aims to retain the highest utility and value of products, components and materials at all times". The model is based on reducing waste of resources to a minimum, which entails preserving and reusing products at the end of their useful life, giving them an added value. Similarly, adaptive reuse aims to improve the architectural, environmental, social and economic qualities of buildings, sites or areas by maximizing the efficiency of existing materials and resources. Consequently, adaptive reuse not only plays a significant role in the regeneration of the built environment, with respect to the conservation of architectural heritage values (Kıran Çakır et. al. 2020), but can also be considered as an essential contribution to achieving circular economies in cities and territories, avoiding the waste of environmental and cultural resources (Della Spina, 2020). Addressing the problem of reuse from an adaptive perspective (Günçea and Misirlisoy 2015, Young and Chan 2012) is an increasingly widespread strategy for existing buildings: extending their life delivers economic benefits to investors (Dyson et al 2016, Douglas 2006) and contributes to global climate protection and emission reduction (Conejos et al 2014, Elefante 2007). More specifically, a sizable body of literature states that adapting a building or an area is cheaper than creating a new one (Douglas 2006, Bullen and Love 2011b, Remøy and Van der Voordt 2007, Kohler and Yang 2007, Oppio et al. 2017). From a sustainability perspective, it is particularly interesting that reuse is encouraged over demolition and reconstruction, since it consumes fewer raw materials, uses less energy, reduces waste and preserves portions of the urban landscape.

Designing potential uses which guarantee the preservation of tangible and intangible aspects as well as sustainable economic development is a complex issue. Likewise, choosing the best scenario, which respects the past and promotes the future, is also a complex and uncertain process that requires methodological evaluation support. The choice of an adaptive reuse scenario, which addresses all the objectives and values of the object in question, is a decision-making problem. Decisions on the allocation of resources for the reuse and conservation of cultural heritage are based on different preferences and interests expressed by different stakeholders, and on a set of multiple criteria (Bottero et al. 2019). Multicriteria approaches are an appropriate methodological framework for addressing the complexity of these problems and the new methodology that we propose and illustrate in the following pages is intended to contribute to the literature on MCDA methods for architectural and urban applications.

\section{The case study}

The Stock Exchange is located in a very accessible point in the center of Turin (Fig. 3). 


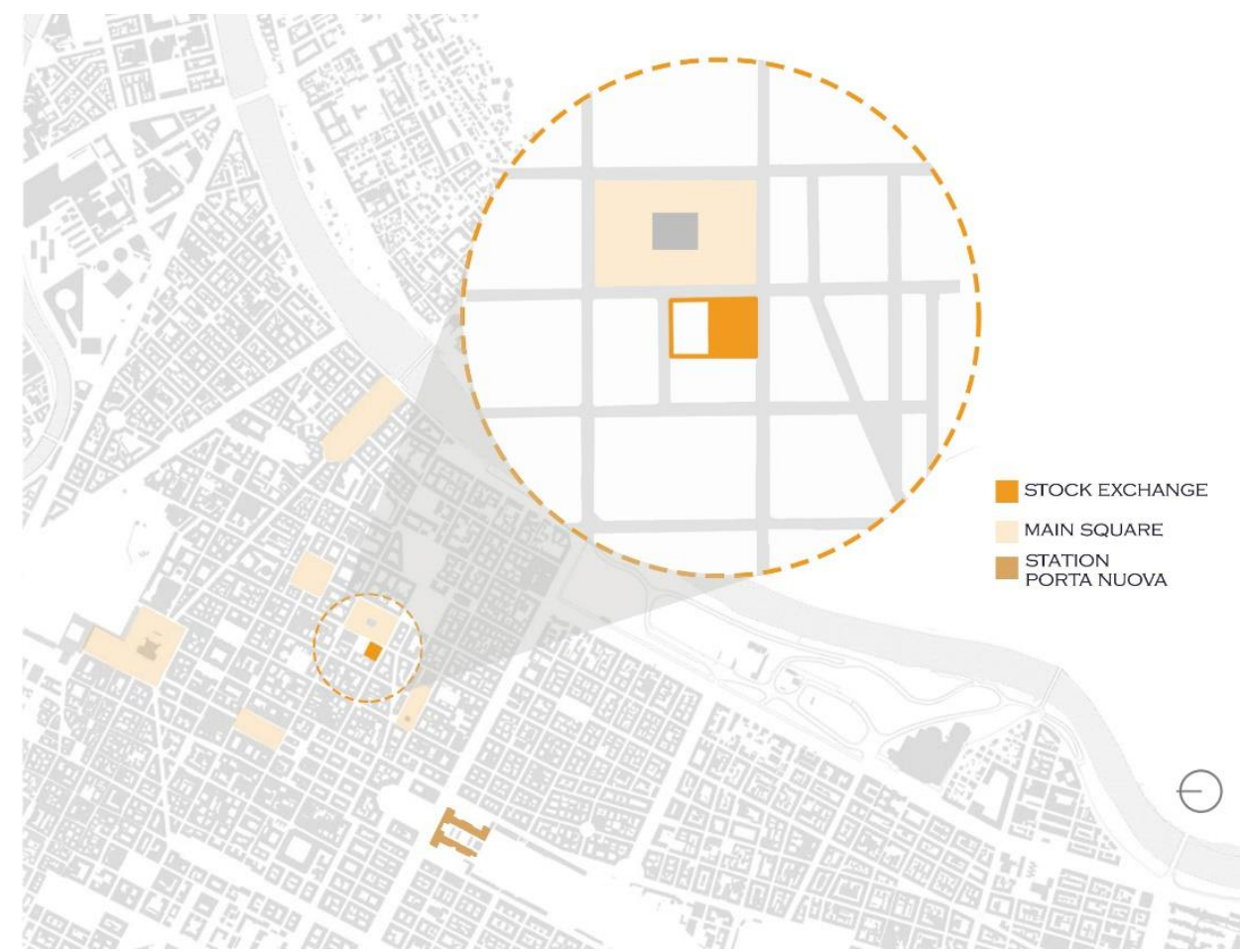

Fig. 3 Stock Exchange building location in the Turin city center.

Designed by two well-known Italian architects, Aimaro Oreglia d'Isola and Roberto Gabetti, the building was constructed between 1952 and 1957 as the new home of the Turin stock exchange. It is considered an iconic building, since it represents a rebellion against the simplified, unornamented forms typical of the Modern Movement in favor of the stylistic freedom shown by Italian taste in the 60s (Papuzzi, 2011). The building is chiefly notable for two distinctive features: the great "Shouts Hall" and its peculiar pavilion vault, which measures about $40 \mathrm{~m}$ per side and employed a particular construction technique.

The "Shouts Hall" was the center of all exchange activities. It covers a surface area of about 1500 square meters and rises to a height of $17 \mathrm{~m}$. Fig. 4 shows the construction of the vault on the left, and a photo of the "Shouts Hall" during its heyday on the right.

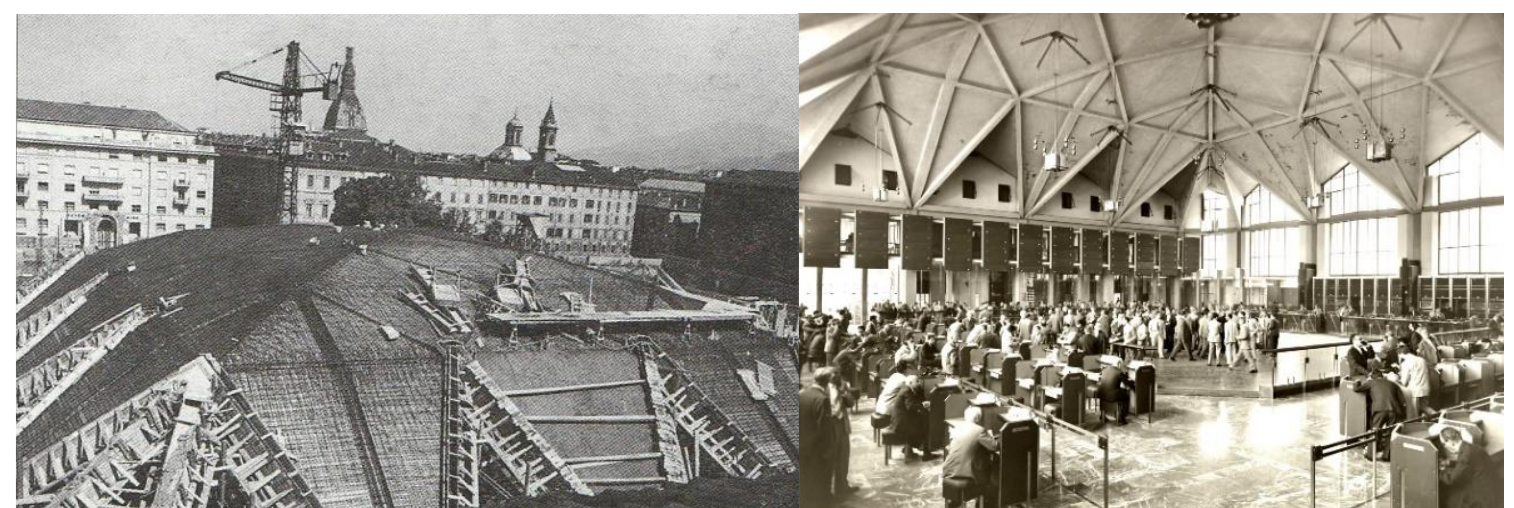

Fig. 4 Construction of the vault, 1955 (left, Alberto Papuzzi, 2011) and the "Shouts Hall" during business hours (right, Chamber of Commerce of Turin documentation, www.to.camcom.it/ex-borsa-valori)

The building also includes a three-story office block, which in the past hosted a wardrobe, a salon, some offices, meeting rooms and the caretaker's quarters.

When electronic trading replaced the open outcry market in 1992, the Stock Exchange lost its function, and it was abandoned in 2008.

Though there was an attempt to convert the building in 2010 and it has been used for a series of temporary artistic events since 2015 , it currently has no function.

It is worth mentioning that since the Superintendency of Archeology, Fine Arts and Landscape for the Metropolitan City of Turin has declared the building to be of "important artistic merit" and one of the two architects, Aimaro Oreglia d'Isola, is still alive, the building is covered by copyright law. This means that the building must be protected from distortion and mutilation and the architect holds the right of attribution. 


\subsection{Defining project alternatives}

Six alternative projects were considered in order to identify the most interesting transformation for the building (Fig. 5). Five were presented by students of the Politecnico di Torino Master's degree program in Architecture Construction and City, while the sixth project was commissioned by the Piedmont regional government and the Turin Chamber of Commerce, which owns the building, and developed by the Politecnico di Torino Department of Architecture and Design. These particular design alternatives were chosen not only because of their innovative character and their proven economic sustainability, but also because of their value in testing the methodology. Indeed, each selected function raises methodological challenges, such as those posed in defining appropriate criteria that also take aspects related to adaptive reuse into account, or in using different units of measurement for each criterion in order to appropriately express the aesthetic and qualitative aspects typical of the architectural sector. Furthermore, these alternatives were discussed with the two DMs for this application, i.e., the two consultants of the Politecnico di Torino project team, who found them to be interesting, plausible and feasible.
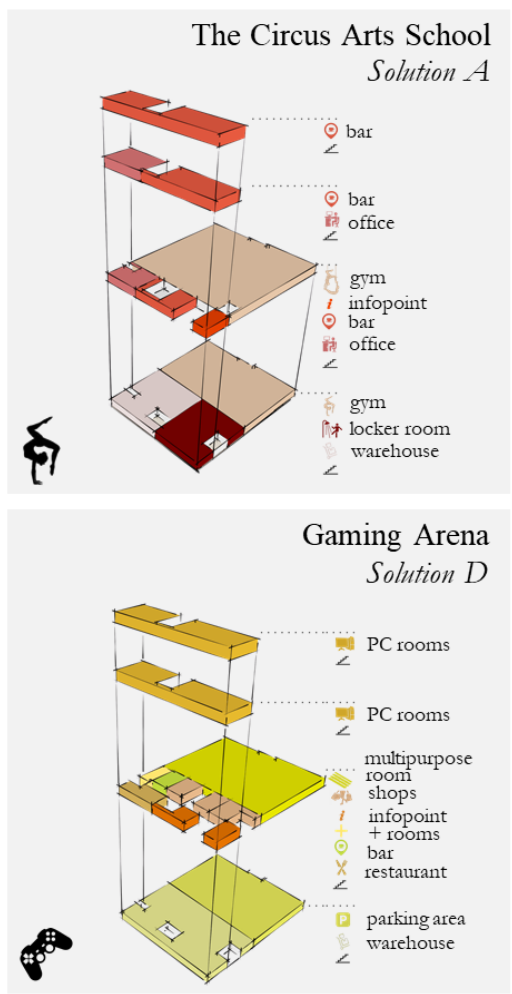
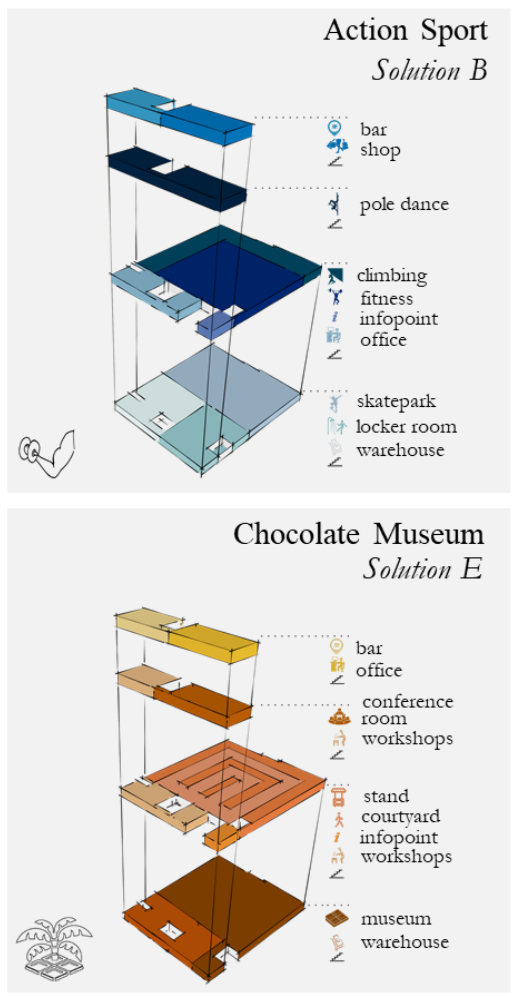
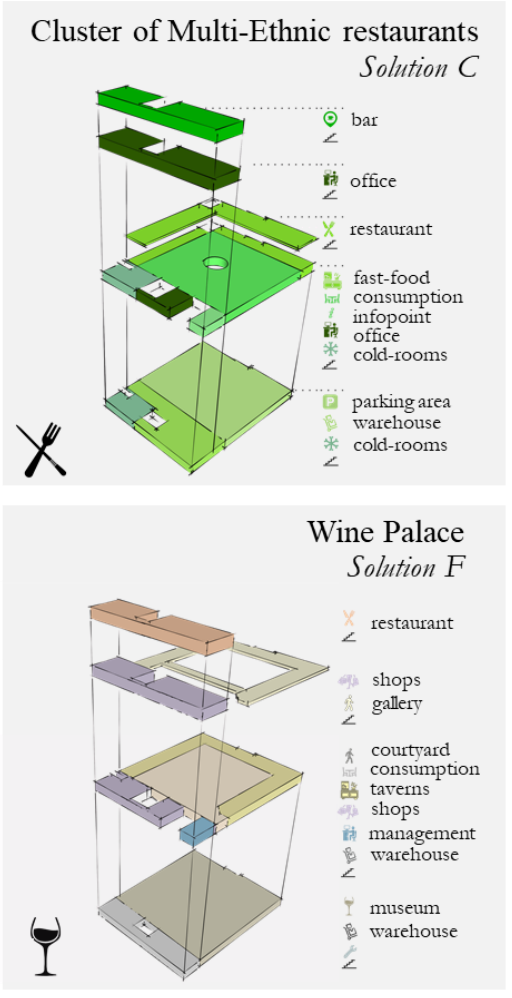

Fig. 5 Exploded axonometric views of the six design alternatives

As can be seen from Fig. 5, the six alternative projects offer a wide range of functions that fall into two macro families:

1) Traditional functions in line with Turin's gastronomic and museum tradition, such as solutions C, E and F:

- Solution $\mathrm{C}$ proposes to transform the former stock exchange into a cluster of ethnic fast food restaurants, in view of the increasing presence of ethnic cultures and their influence on Italians' eating habits. The "Shouts Hall"'s great height is turned to advantage by adding a mezzanine level which could house an Italian restaurant. Moreover, in addition to the offices and the storage area, the office block will feature a bar area on the top floor which will also have access to the terrace with a panoramic view of the cityscape.

- Solution E proposes to transform the basement of the stock exchange into a chocolate museum named Chocolate Island. The "Shouts Hall" would be partitioned semi-reversibly into 24 individual retail stalls. Spaces for teaching workshops, a conference room, offices and a bar area would be provided in the former office block.

- Solution F proposes to transform the building into a wine museum combined with taverns and a gourmet restaurant. The "Shouts Hall" would be converted into a covered square surrounded by the 
taverns and used for visual narratives and events. As for solution E, the museum and the spaces for teaching workshops would be located in the basement, while three shops and the gourmet restaurant would be hosted in the former office block.

2) Innovative solutions proposing entertainment activities, such as solutions A, B and D. Specifically:

- Solution A would be the new Circus Arts School. The large single free space of the "Shouts Hall" with its great height of $17 \mathrm{~m}$ is ideal the use of the flying trapeze-which must be secured by a rope at least $3 \mathrm{~m}$ long and $7.2 \mathrm{~m}$ from the ground-and for the installation of a removable grandstand to accommodate the public during the events. The basement level would be used as a gym for the various courses and the office block would house a bar area on three levels and an office area on the first and second level.

- Solution B would offer functions chiefly targeting a young public, or a multi-sport center, equipped for extreme sports such as skateboarding, climbing, pole dance and fitness gym. The height of the "Shouts Hall" can be exploited to install a double-height climbing wall, while the first floor and basement provide abundant space for a fitness area and a skate park. The office block would provide space for a pole dance studio, a bar area and a sporting goods shop.

- Solution D is the Gaming Arena, in view of the fast growing international market for e-games at a competitive and professional level. The Stock Exchange will house the new video games center as a meeting place and space for dialog on eSport. The former "Shouts Hall" would become into the new multi-purpose hall hosting national and international tournaments or extra events. The office block would house three e-game shops, while a bar, a restaurant area and PC rooms would be located on the top two floors.

As regards work on the building, all projects call for restoring the facades, installing new utilities and acoustic and thermal insulation to make the building usable and, lastly, installing the equipment needed for the various activities.

\section{Structuring the decision-aiding process}

We then proceeded to structure the decision-aiding process for identifying the solution that best reflects the DMs' preferences. It should be borne in mind that this model has certain limitations, as it is applied to a fairly small set of alternatives and it was not possible to interface with the property's real DMs, i.e., the Turin Chamber of Commerce and the Piedmont regional government. However, the choice of alternatives and the fact that two consultants of the Politecnico di Torino project team acted as DMs in the real ongoing process and were aware of the real DMs' actual preferences allowed us to arrive at a realistic application. This section describes the decision-making process conducted according to the methodological framework explained in section 2 .

\subsection{Criteria, sub-criteria and evaluation matrix}

The alternative projects were evaluated on a coherent, exhaustive and non-redundant set of criteria (Roy and Bouyssou, 1993). These criteria were defined on the basis of the building's features and the literature concerning the synthesis of problems into criteria or clusters of criteria (Martin and Lagret 2005, Abastante and Lami 2013, Bottero et al. 2015, Abastante 2016, Camoletto et al. 2017, Abastante et al. 2018, Costa et al. 2019).

A set of four macro-criteria were defined, which are in turn made up of eight quali-quantitative sub-criteria as shown in Table 1. These sub-criteria were defined from the perspective of the property owner, the Turin Chamber of Commerce.

Table 1 Criteria, sub-criteria and associated units of measure

\begin{tabular}{|c|c|c|c|c|c|}
\hline $\mathbf{G}_{\mathbf{N}}$ & $\begin{array}{l}\text { Macro- } \\
\text { Criteria }\end{array}$ & $\mathbf{g n}$ & Sub-criteria & Units of measure & $\begin{array}{c}\text { Preference } \\
\text { direction of } g_{n}\end{array}$ \\
\hline \multirow{2}{*}{$\mathrm{G}_{\mathrm{T}}$} & \multirow{2}{*}{ Technical } & $\mathrm{g}_{\mathrm{T} 1}$ & Intended use innovation & Ordinal scale & $\uparrow$ \\
\hline & & $\mathrm{g}_{\mathrm{T} 2}$ & Work Duration & Months & $\downarrow$ \\
\hline \multirow{3}{*}{$\mathrm{G}_{\mathrm{E}}$} & \multirow{3}{*}{ Economic } & $\mathrm{g}_{\mathrm{E} 1}$ & Maintenance Cost & $\%$ & $\downarrow$ \\
\hline & & $\mathrm{g}_{\mathrm{E} 2}$ & Net Present Value & $€$ & $\uparrow$ \\
\hline & & $\mathrm{g}_{\mathrm{E} 3}$ & Pay Back Period & Years & $\downarrow$ \\
\hline \multirow{2}{*}{$\mathrm{G}_{\mathrm{R}}$} & \multirow{2}{*}{ Reuse } & $\mathrm{g}_{\mathrm{R} 1}$ & Impact on architectural value & $\%$ & $\downarrow$ \\
\hline & & $\mathrm{g}_{\mathrm{R} 2}$ & Physical impact & Dichotomous scale & $\downarrow$ \\
\hline $\mathrm{G}_{\mathrm{S}}$ & Social & $\mathrm{g}_{\mathrm{S} 1}$ & Human resources & Numbers & $\uparrow$ \\
\hline
\end{tabular}


The criteria were organized in a hierarchical structure as called for by the MCHP. As can be seen in Fig. 6, the main issue, i.e., the choice of the transformation project, was unpacked into four macro-criteria followed by the eight sub-criteria.

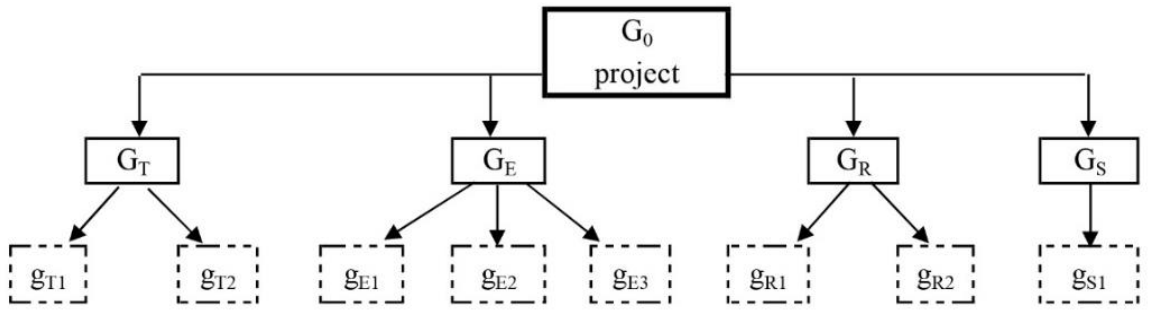

Fig. 6 Hierarchical structure of criteria

A graphical representation with a brief description of the sub-criteria is set out in Table 2: the column headed "evaluation" shows a representative picture of each sub-criterion's performance of the alternatives with, from left to right, the alternatives, performance flow lines and the corresponding value, expressed according to the predefined unit of measurement.

Table 2 Graphical representation of the evaluation matrix of all design solutions

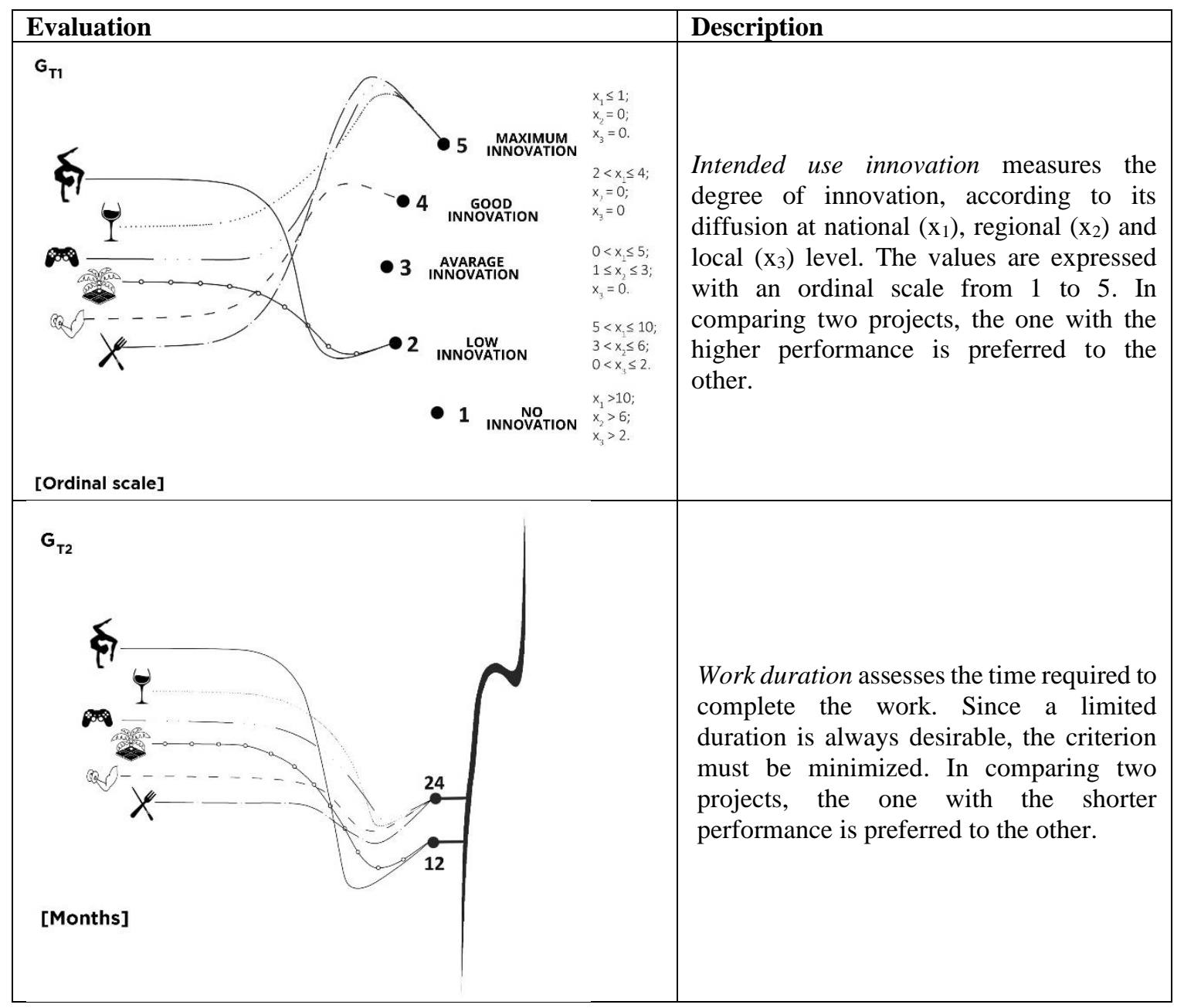




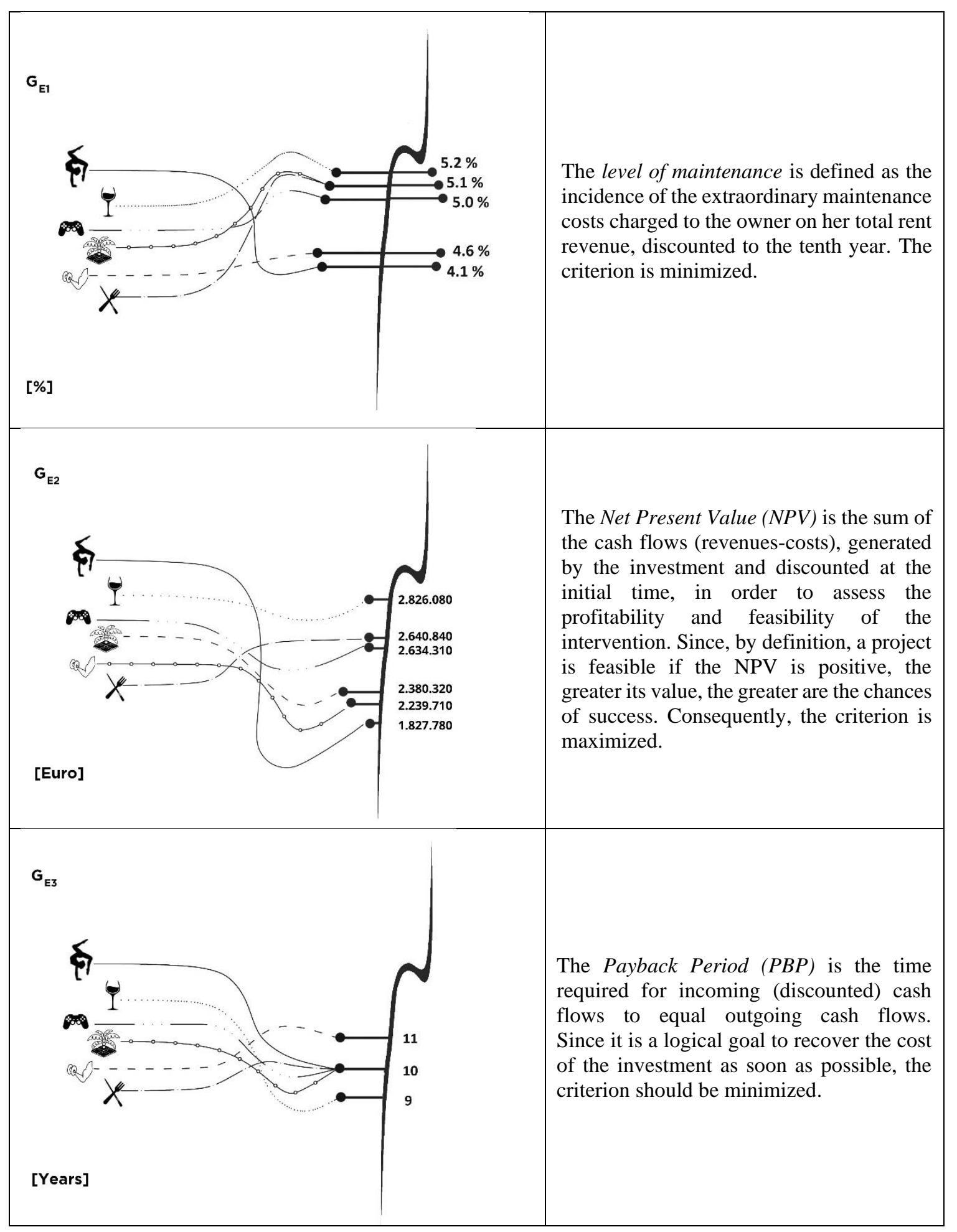




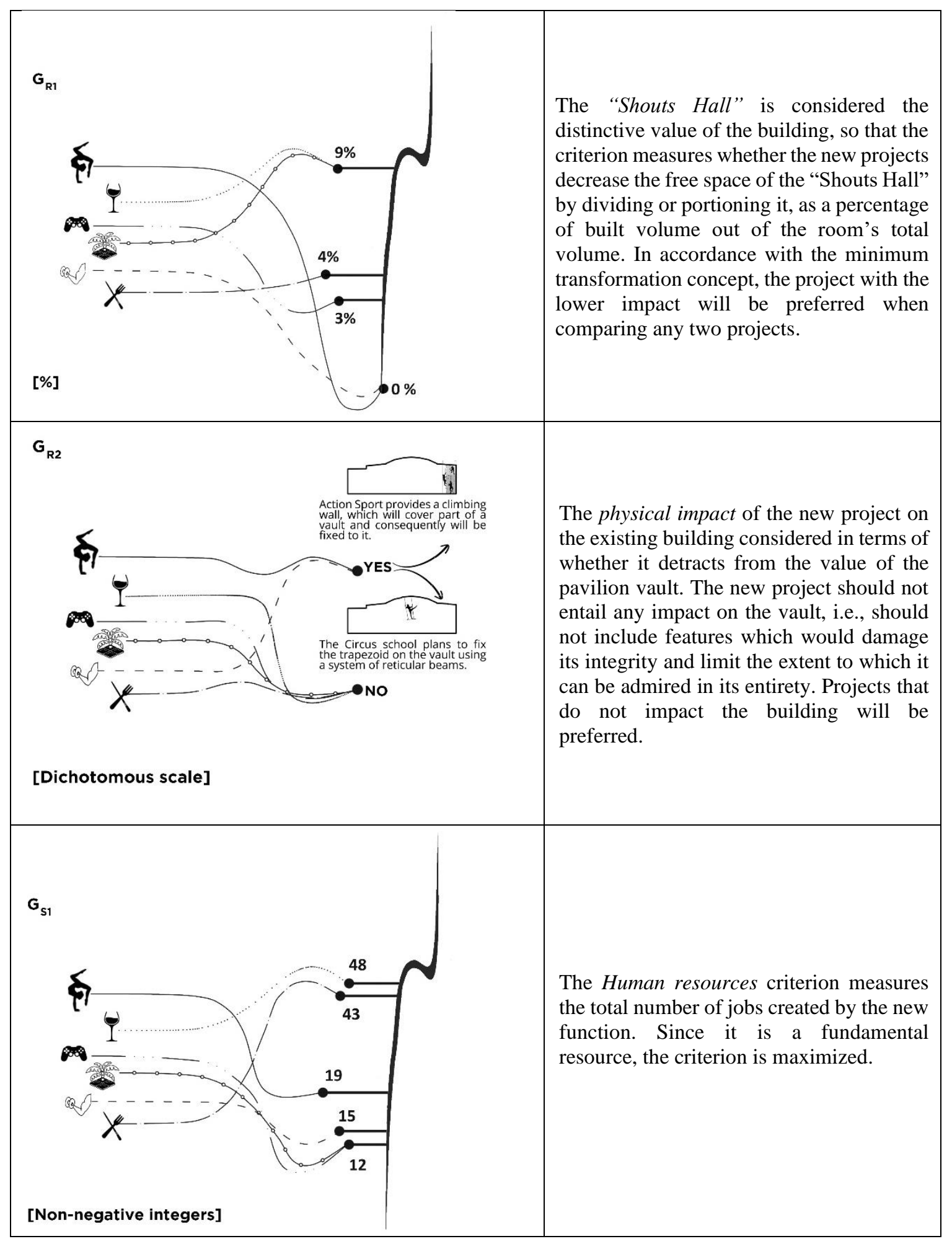

Table 3 summarizes the performance matrix of the six projects for each elementary criterion.

Table 3 Performance matrix

\begin{tabular}{|l|c|c|c|c|c|c|}
\cline { 2 - 7 } \multicolumn{1}{c|}{} & $\mathbf{A}$ & $\mathbf{B}$ & $\mathbf{C}$ & $\mathbf{D}$ & $\mathbf{E}$ & $\mathbf{F}$ \\
\hline $\mathbf{g}_{\mathbf{T} 1}$ & 2 & 4 & 5 & 5 & 2 & 5 \\
\hline $\mathbf{g}_{\mathbf{T} 2}$ & 12 & 24 & 24 & 24 & 12 & 24 \\
\hline $\mathbf{g}_{\mathbf{E} 1}$ & $4.1 \%$ & $4.6 \%$ & $5.1 \%$ & $5.0 \%$ & $5.1 \%$ & $5.2 \%$ \\
\hline
\end{tabular}




\begin{tabular}{|l|c|c|c|c|c|c|}
$\mathbf{g}_{\mathbf{E} 2}$ & $€ 1,827,779$ & $€ 2,239,710$ & $€ 2,640,840$ & $€ 2,634,312$ & $€ 2,380,323$ & $€ 2,826,078$ \\
\hline $\mathbf{g}_{\mathbf{E} 3}$ & 10 & 11 & 10 & 10 & 10 & 9 \\
\hline $\mathbf{g}_{\mathbf{R} 1}$ & $0 \%$ & $0 \%$ & $4 \%$ & $3 \%$ & $9 \%$ & $9 \%$ \\
\hline $\mathbf{g}_{\mathbf{R} 2}$ & yes (1) & yes (1) & no (0) & no (0) & no (0) & no (0) \\
\hline $\mathbf{g}_{\mathbf{S} 1}$ & 19 & 15 & 43 & 12 & 12 & 48 \\
\hline
\end{tabular}

\subsection{Decision makers and discrimination thresholds}

As mentioned earlier, the DMs were two consultants of the Politecnico di Torino project team who acted as intermediaries with the real client in defining the set of preferences needed to apply the methodological framework. They were asked to provide different types of preference information: four meetings were needed over the course of about two months to arrive at a complete picture of the preferences.

First, the project alternatives and the evaluation criteria were presented to the DMs. Second, they were asked to express the discrimination thresholds; third, they were asked to provide information about possible mutualstrengthening and mutual-weakening effects, as well as about the possible antagonistic effects between certain elementary criteria. Fourth, they applied the imprecise SRF-II method about the subset of criteria descending from each criterion in the hierarchy and sited at the level immediately below it.

Regarding the discrimination thresholds, Table 4 shows the indifference $q$, preference $p$ and veto $v$ thresholds expressed by the DMs for each criterion.

Table 4 Discrimination thresholds expressed by DMs

\begin{tabular}{|c|c|c|c|c|c|c|}
\hline $\mathbf{g}_{\mathbf{n}}$ & Units of measure & \multicolumn{2}{|c|}{ Scale } & indifference & preference & veto \\
\hline $\mathbf{g}_{\mathrm{T} 1}$ & Ordinal scale & $(1-5)$ & & 1 & 2 & - \\
\hline $\mathbf{g}_{\mathrm{T} 2}$ & Months & $(1-\infty)$ & & 12 & 24 & 36 \\
\hline$g_{E 1}$ & $\%$ & $(1-100 \%)$ & & $0.1 \%$ & $0.3 \%$ & $17 \%$ \\
\hline$g_{\mathrm{E} 2}$ & $€$ & $(0-\infty)$ & & 100,000 & 200,000 & $1,000,000$ \\
\hline \multirow{2}{*}{ gE3 } & \multirow{2}{*}{ Years } & \multirow{2}{*}{$(1-\infty)$} & Until 5 & \multirow{2}{*}{1} & 4 & \multirow{2}{*}{15} \\
\hline & & & Over 5 & & 2 & \\
\hline $\mathbf{g}_{\mathrm{R} 1}$ & $\%$ & $(1-100 \%)$ & & $0.5 \%$ & $1 \%$ & $10 \%$ \\
\hline$g_{R 2}$ & Dichotomous scale & Yes/No & & - & - & - \\
\hline \multirow{2}{*}{ gs1 } & \multirow{2}{*}{ Numbers } & \multirow{2}{*}{$(1-\infty)$} & Until 20 & 1 & 2 & \multirow{2}{*}{10} \\
\hline & & & Over 20 & 4 & 7 & \\
\hline
\end{tabular}

It should be noted that $\mathrm{q}, \mathrm{p}$ and $\mathrm{v}$ thresholds can be variable according to the alternatives' performance for the criterion at hand. For example, the DMs expressed the following payback period preference threshold for criterion $\mathrm{g}_{\mathrm{E} 3}$ :

- if $G_{E 3}(a) \leq 5$, then $p_{E 3}(a)=4$ (to be strictly preferred to $a$, an alternative $b$ must have a payback period at least 4 years shorter than $a)$.

- if $G_{E 3}(a)>5$, then $P_{E 3}(a)=2$ (to be preferred to $a$, an alternative $b$ must have a payback period at least 2 years shorter than $a$ ).

As sub-criterion $\mathrm{g}_{\mathrm{R} 2}$ is measured on a dichotomous scale, it does not require preference and indifference thresholds.

\subsection{Interaction between criteria}

Two criteria may interact with each other by presenting a mutual-strengthening effect, a mutual-weakening effect or an antagonistic effect (Figueira et al. 2009). We first explained the meaning of these three types of interaction to the DMs:

- Mutual-strengthening effect: if two criteria $\mathrm{g}_{\mathrm{i}}$ and $\mathrm{g}_{\mathrm{j}}$, both relevant to a DM, are in favor of the assertion aSb (a outranks b), i.e., alternative $a$ is at least as good as alternative b, it must be taken into account that their contribution (weight) has to be greater than the sum $w_{i}+w_{j}$ of their weights $w_{i}$ and $\mathrm{w}_{\mathrm{j}}$, respectively.

- Mutual-weakening effect: if two criteria $g_{i}$ and $g_{j}$, both relevant to a DM but closely interconnected and dependent on each other, are in favor of the assertion aSb, it must be taken into account that their contribution (weight) must be smaller than the sum $w_{i}+w_{j}$ of their weights. 
- Antagonistic effect: if the criterion $g_{i}$ supports the $\mathrm{aSb}$ assertion and the $\mathrm{g}_{\mathrm{h}}$ criterion, strongly opposes the $\mathrm{aSb}$ assertion, then the contribution of the $\mathrm{g}_{\mathrm{i}}$ criterion must be considered smaller than its weight $\mathrm{W}_{\mathrm{i}}$.

Second, to help DMs correctly understand and explain these mutual relationships, some possible interactions between the set of criteria were presented to them. The DMs were free to state their agreement or disagreement and present further interaction on the basis of their technical knowledge. As shown in Table 5, the DMs expressed four strengthening effects, one weakening effect and one antagonistic effect.

Table 5 Interaction between the criteria

\begin{tabular}{|c|c|c|c|c|c|}
\hline $\mathbf{g n}_{\mathbf{n}}$ & Criterion 1 & $\mathbf{g n}_{\mathbf{n}}$ & Criterion 2 & Interaction & Description \\
\hline $\mathbf{g}_{\mathbf{T 1}}$ & $\begin{array}{l}\text { Intended use } \\
\text { innovation }\end{array}$ & $\mathbf{g}_{\mathbf{T} 2}$ & Work Duration & $\begin{array}{l}\text { Mutual- } \\
\text { Strengthening } \\
\text { effect }\end{array}$ & $\begin{array}{l}\text { If a project has both a high innovation of } \\
\text { intended use and a short work duration, the } \\
\text { importance of the two criteria together must } \\
\text { be considered greater than the sum of their } \\
\text { importance when they are considered alone. }\end{array}$ \\
\hline gR1 & $\begin{array}{l}\text { Impact on } \\
\text { architectural } \\
\text { value }\end{array}$ & gR2 & Physical impact & $\begin{array}{l}\text { Mutual- } \\
\text { Strengthening } \\
\text { effect }\end{array}$ & $\begin{array}{l}\text { If a project has a low impact on the } \\
\text { architectural value of the building and a low } \\
\text { physical impact, the importance of the two } \\
\text { criteria must be considered greater than the } \\
\text { sum of their importance when they are } \\
\text { considered alone. }\end{array}$ \\
\hline gE2 & NPV & $\mathbf{g}_{\mathbf{R} 1}$ & Physical impact & $\begin{array}{c}\text { Antagonistic } \\
\text { effect }\end{array}$ & $\begin{array}{l}\text { If a project has better income performance } \\
\text { than another, but has a higher impact on the } \\
\text { building, the contribution of the Net Present } \\
\text { Value criterion must be considered less than } \\
\text { its weight. }\end{array}$ \\
\hline gE2 & NPV & gs1 & $\begin{array}{l}\text { Human } \\
\text { resources }\end{array}$ & $\begin{array}{l}\text { Mutual- } \\
\text { Strengthening } \\
\text { effect }\end{array}$ & $\begin{array}{l}\text { If a project has better income performance } \\
\text { than another and also provides more jobs, } \\
\text { the importance of the two criteria must be } \\
\text { considered greater than the sum of their } \\
\text { importance when they are considered alone. }\end{array}$ \\
\hline gT1 & $\begin{array}{l}\text { Intended use } \\
\text { innovation }\end{array}$ & gE3 & PBP & $\begin{array}{l}\text { Mutual- } \\
\text { Strengthening } \\
\text { effect }\end{array}$ & $\begin{array}{l}\text { If a project has both a higher innovation of } \\
\text { intended use and a shorter payback period } \\
\text { than another, the importance of the two } \\
\text { criteria must be considered greater than the } \\
\text { sum of their importance when they are } \\
\text { considered alone. }\end{array}$ \\
\hline gE3 & PBP & gE2 & NPV & $\begin{array}{c}\text { Mutual- } \\
\text { Weakening } \\
\text { effect }\end{array}$ & $\begin{array}{l}\text { If a project has a short payback period, it is } \\
\text { also likely to have a positive NPV, so the } \\
\text { importance of the two criteria must be } \\
\text { considered lower than the sum of their } \\
\text { importance when they are considered alone. }\end{array}$ \\
\hline
\end{tabular}

\subsection{Prioritization of all criteria/sub-criteria and the new SRF-II method}

The last essential preferential information required by the methodology entails applying the SRF-II method to define the set of feasible weights of the criteria and sub-criteria.

To simplify the required information and reduce the cognitive burden for the DMs from whom we had to elicit the criteria weights, we applied the SRF-II method based on the number of blank cards $e_{0}$ between the "zero criterion" and the least important criteria introduced in Section 2.3.

Since all DMs have their own opinions and preferences, it is interesting to observe how the results of the application differ when input values are changed. Accordingly, the SRF-II method was first applied separately for each DM, after which the DMs were required to interact with each other to provide a common classification of the criteria and of the sub-criteria. The set of common preferences was as follows:

- For the first hierarchical level criteria $\left(G_{T}, G_{E}, G_{R}\right.$ and $\left.G_{S}\right)$, the experts specify that since the building in question is a public good, social and economic factors take priority. Accordingly, they indicated that $\mathrm{G}_{\mathrm{T}}$ is less important than $\mathrm{G}_{\mathrm{R}}$, which in turn is less important than $\mathrm{G}_{\mathrm{S}}$, which is overtaken by $\mathrm{G}_{\mathrm{E}}$. No blank cards were inserted between $G_{T}$ and $G_{R}$, while the number of the blank cards between $G_{R}$ 
and $G_{S}$ belongs to the interval [2,3] and those between $G_{S}$ and $G_{E}$ belong to the interval $[0,1]$. Moreover, the DMs decided to insert 3 blank cards between the less important criterion $\left(\mathrm{G}_{\mathrm{T}}\right)$ and the "zero criterion" $\left(e_{0}=3\right)$. Therefore the ratio $\mathrm{z}$ is in the interval $[9,11]$.

- For the macro-criterion $\mathrm{G}_{\mathrm{T}}$, the DMs indicated that $\mathrm{g}_{\mathrm{T} 1}$ is not a binding factor but an added value for the project, and thus ranks after criterion $\mathrm{g}_{\mathrm{T} 2}$. The blank cards inserted between them belong to the interval $[2,4]$. The DMs inserted 1 blank card between the criterion $\mathrm{g}_{\mathrm{T} 1}$ and the "zero criterion" $\left(e_{0}=1\right)$ and the ratio $\mathrm{z}$ thus belongs to the interval [5,7].

- For macro-criterion $\mathrm{G}_{\mathrm{E}}$, the DMs ranked criteria $\mathrm{g}_{\mathrm{E} 2}$ and $\mathrm{g}_{\mathrm{E} 3}$ ex-aequo at the first level, since the NPV and the PBP are factors that express the project's solidity. Criterion $\mathrm{g}_{\mathrm{E} 1}$ is less troubling if the project scores a positive NPV, so it is ranked last. Two blank cards were inserted between $\mathrm{g}_{\mathrm{E} 1}$ and $\left\{\mathrm{g}_{\mathrm{E} 2}, \mathrm{~g}_{\mathrm{E} 3}\right\}$. The DMs decided that at least 1 and at most 3 blank cards should be added between the less important criteria $\left(\mathrm{g}_{\mathrm{E} 1}\right)$ and the "zero - criterion" $\left(e_{0} \in[1,3]\right)$, and the ratio $\mathrm{z}$ thus belongs to the interval $[5,7]$.

- For macro-criterion $G_{R}$, DMs ranked $g_{R 1}$ at the last place after $g_{R 2}$. The latter is the most relevant criterion since the vault is the building's distinctive feature and its value should thus be preserved. The blank cards inserted between them belong to the interval [0,1]. The DMs inserted 1 blank card between criterion $\mathrm{g}_{\mathrm{R} 1}$ and the "zero criterion" $\left(e_{0}=1\right)$; consequently, the ratio $\mathrm{z}$ belongs to the interval $[3,4]$.

- As macro-criterion Gs provides only one sub-criterion, there is no need to express a preference ranking.

\section{Final results}

In light of the preference information provided by the DMs and presented in the previous section, we checked if there is at least one vector of parameters compatible with this preference, and found that there was. To ensure robust recommendations, the SMAA methodology was applied to summarize the results of the hierarchical ELECTRE III method with interactions, obtained by sampling 10,000 compatible vectors. Consequently, the methodology provides several different partial pre-orders of alternatives compatible with the preferences expressed by the DMs, with the relative frequencies with which they occurred. For each partial pre-order considered, we computed the barycenter of the set of parameter vectors restoring it; this barycenter, containing the weights of criteria $w_{i}$ of criteria $g_{i}$ and the interaction coefficients $w_{i j}$ of criteria $g_{i}$ and $g_{j}$, represents the average preferences provided by the DMs for which the pre-order is obtained. In addition to the most frequent partial pre-orders, the methodology provides the frequency with which an alternative is preferred, indifferent or incomparable for each non-elementary criterion and for the root criterion.

Here we report the comprehensive level results obtained by considering the preferences provided by the two DMs together; similar results for the other four macro-criteria in the hierarchy are given in the appendix.

Computing one partial pre-order for each of the 10,000 compatible vectors gives 13 different partial pre-orders. The three which are obtained most frequently are shown in Fig. 7-9. In particular, these three pre-orders appear in $67.34 \%, 12.54 \%$ and $10.67 \%$ of the cases, respectively. Consequently, the other ten partial pre-orders are obtained, together, in the remaining $9.45 \%$ of the cases. 
Wine Palace (F)

Multi-ethnic restaurants (C)<smiles>[13CH3]</smiles>

Gaming Arena (D)

Action Sport (B)

Circus Arts School (A)

Chocolate Island (E)

Fig. 7 Most frequent (67.34\%) partial pre-order at comprehensive level
Wine Palace (F)<smiles>C[13CH2]</smiles>

Multi-ethnic restaurants (C)

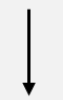

Gaming Arena (D)

Action Sport (B)

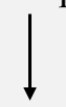

Circus Arts School (A)<smiles>[13CH2]I</smiles>

Chocolate Island (E)

Fig. 8 Second most frequent partial pre-order at comprehensive level obtained with a frequency of $12.54 \%$
Wine Palace (F)<smiles>C[13CH2]</smiles>

Multi-ethnic restaurants (C)<smiles>[13CH2]I</smiles>

Gaming Arena (D)<smiles>[Te]C1CC1</smiles>

Circus Arts School (A)

Action Sport (B)<smiles>[13CH3]</smiles>

Chocolate Island (E)

Fig. 9 Third most frequent (10.67\%) partial pre-order at comprehensive level

Looking at the figures, we can see that Wine Palace is always in the first place in the three rankings and shares the first position with Multi-ethnic restaurants in the most frequent partial pre-order. Similarly, Chocolate Island is the least preferred option in the three most frequent partial pre-orders.

As can be seen from Table 6, the Wine Palace project is preferred to all other alternatives, apart from MultiEthnic Restaurant project, in all cases. These two projects are quite often indifferent (70.85\% in Table 5), Wine Palace is preferred to Multi-Ethnic Restaurant with a frequency of $25.28 \%$, while the opposite is true in the remaining cases $(3.87 \%$ in Table 6).

Table 5 Frequency of indifference

\begin{tabular}{|c|c|c|c|c|c|c|}
\hline & $\boldsymbol{A}$ & $\boldsymbol{B}$ & $\boldsymbol{C}$ & $\boldsymbol{D}$ & $\boldsymbol{E}$ & $\boldsymbol{F}$ \\
\hline $\boldsymbol{A}$ & 0 & 17.44 & 0 & 0 & 0 & 0 \\
\hline $\boldsymbol{B}$ & 17.44 & 0 & 0 & 80.07 & 0 & 0 \\
\hline $\boldsymbol{C}$ & 0 & 0 & 0 & 0 & 0 & 70.85 \\
\hline $\boldsymbol{D}$ & 0 & 80.07 & 0 & 0 & 0 & 0 \\
\hline $\boldsymbol{E}$ & 0 & 0 & 0 & 0 & 0 & 0 \\
\hline $\boldsymbol{F}$ & 0 & 0 & 70.85 & 0 & 0 & 0 \\
\hline
\end{tabular}

Table 6 Frequency of preference

\begin{tabular}{|c|c|c|c|c|c|c|}
\hline & $\boldsymbol{A}$ & $\boldsymbol{B}$ & $\boldsymbol{C}$ & $\boldsymbol{D}$ & $\boldsymbol{E}$ & $\boldsymbol{F}$ \\
\hline $\boldsymbol{A}$ & 0 & 0 & 0 & 0 & 100 & 0 \\
\hline $\boldsymbol{B}$ & 82.56 & 0 & 0 & 0.49 & 100 & 0 \\
\hline $\boldsymbol{C}$ & 100 & 100 & 0 & 100 & 100 & 3.87 \\
\hline $\boldsymbol{D}$ & 97.36 & 17.29 & 0 & 0 & 100 & 0 \\
\hline $\boldsymbol{E}$ & 0 & 0 & 0 & 0 & 0 & 0 \\
\hline $\boldsymbol{F}$ & 100 & 100 & 25.28 & 100 & 100 & 0 \\
\hline
\end{tabular}

Table 7 Frequency of incomparability

\begin{tabular}{|l|c|c|c|c|c|c|}
\hline & $\boldsymbol{A}$ & $\boldsymbol{B}$ & $\boldsymbol{C}$ & $\boldsymbol{D}$ & $\boldsymbol{E}$ & $\boldsymbol{F}$ \\
\hline $\boldsymbol{A}$ & 0 & 0 & 0 & 2.64 & 0 & 0 \\
\hline $\boldsymbol{B}$ & 0 & 0 & 0 & 2.15 & 0 & 0 \\
\hline $\boldsymbol{C}$ & 0 & 0 & 0 & 0 & 0 & 0 \\
\hline $\boldsymbol{D}$ & 2.64 & 2.15 & 0 & 0 & 0 & 0 \\
\hline
\end{tabular}




\begin{tabular}{|l|l|l|l|l|l|l|}
\hline $\boldsymbol{E}$ & 0 & 0 & 0 & 0 & 0 & 0 \\
\hline $\boldsymbol{F}$ & 0 & 0 & 0 & 0 & 0 & 0 \\
\hline
\end{tabular}

As indicated above, for each partial pre-order, we computed the barycenter of the set of parameter vectors for which the ELECTRE III method provided a ranking. As can be seen from the values in Table 8, the weight given to the elementary criteria is nearly the same in the three barycenters. What makes the partial pre-orders different is the value assigned to the coefficients representing the interaction and antagonistic effects. Indeed, in the three barycenters, the interaction effect presenting the highest value is that between Net Present Value $\left(g_{E_{2}}\right)$ and Human Resources $\left(g_{S_{1}}\right)$.

Table 8 Barycenters of the set of parameter vectors giving a certain partial pre-order at comprehensive level

\begin{tabular}{|c|c|c|c|c|c|c|c|}
\hline \multicolumn{8}{|c|}{ Most frequent partial pre-order } \\
\hline \multicolumn{2}{|c|}{$\mathrm{G}_{\mathrm{T}}$} & \multicolumn{3}{|c|}{$\mathrm{G}_{\mathrm{E}}$} & \multicolumn{2}{|c|}{$\mathrm{G}_{\mathrm{R}}$} & Gs \\
\hline \multicolumn{2}{|c|}{0.068} & \multicolumn{3}{|c|}{0.445} & \multicolumn{2}{|c|}{0.132} & 0.355 \\
\hline $\mathrm{g}_{\mathrm{T} 1}$ & $\mathrm{~g}_{\mathrm{T} 2}$ & $g_{\mathrm{E} 1}$ & $\mathrm{~g}_{\mathrm{E} 2}$ & $\mathrm{~g}_{\mathrm{E} 3}$ & $\mathrm{~g}_{\mathrm{R} 1}$ & $\mathrm{~g}_{\mathrm{R} 2}$ & $\mathrm{~g}_{\mathrm{S} 1}$ \\
\hline $\mathrm{w}_{11}$ & $\mathrm{~W}_{12}$ & $\mathrm{w}_{21}$ & $\mathrm{w}_{22}$ & $\mathrm{~W}_{23}$ & $\mathrm{w}_{31}$ & $\mathrm{w}_{32}$ & $\mathrm{~W}_{41}$ \\
\hline 0.108 & 0.038 & 0.070 & 0.147 & 0.147 & 0.067 & 0,115 & 0,308 \\
\hline \multicolumn{4}{|c|}{ Strengthening } & \multicolumn{2}{|c|}{ Weakening } & \multicolumn{2}{|c|}{ Antagonism } \\
\hline $\mathrm{g}_{\mathrm{T} 1 .} \mathrm{g}_{\mathrm{T} 2}$ & $\mathrm{~g}_{\mathrm{T} 1 .} \mathrm{g}_{\mathrm{E} 3}$ & $\begin{array}{c}\mathrm{g}_{\mathrm{E} 2} \\
\mathrm{~g}_{\mathrm{S} 1}\end{array}$ & $\mathrm{~g}_{\mathrm{R} 1 .} \mathrm{g}_{\mathrm{R} 2}$ & \multicolumn{2}{|c|}{$\mathrm{g}_{\mathrm{E} 2 .} \mathrm{g}_{\mathrm{E} 3}$} & \multicolumn{2}{|c|}{$\mathrm{g}_{\mathrm{E} 2 .} \mathrm{g}_{\mathrm{R} 3}$} \\
\hline $\mathrm{W}_{11 \_12}$ & $\mathrm{~W}_{11 \_23}$ & $\mathrm{~W}_{22 \_41}$ & $\mathrm{~W}_{31 \_32}$ & \multicolumn{2}{|c|}{$\mathrm{W}_{22} 23$} & \multicolumn{2}{|c|}{$\mathrm{W}_{22}{ }_{2} 32$} \\
\hline 0.131 & 0.194 & 0.353 & 0.090 & \multicolumn{2}{|c|}{-0.032} & \multicolumn{2}{|c|}{0.040} \\
\hline \multicolumn{8}{|c|}{ Second most frequent partial pre-order } \\
\hline \multicolumn{2}{|c|}{$\mathrm{G}_{\mathrm{T}}$} & \multicolumn{3}{|c|}{$\mathrm{G}_{\mathrm{E}}$} & \multicolumn{2}{|c|}{$\mathrm{G}_{\mathrm{R}}$} & Gs \\
\hline \multicolumn{2}{|c|}{0.068} & \multicolumn{3}{|c|}{0.445} & \multicolumn{2}{|c|}{0.132} & 0.355 \\
\hline $\mathrm{g}_{\mathrm{T} 1}$ & $\mathrm{~g}_{\mathrm{T} 2}$ & $\mathrm{~g}_{\mathrm{E} 1}$ & $\mathrm{~g}_{\mathrm{E} 2}$ & $\mathrm{~g}_{\mathrm{E} 3}$ & $g_{\mathrm{R} 1}$ & $\mathrm{~g}_{\mathrm{R} 2}$ & $\mathrm{~g}_{\mathrm{S} 1}$ \\
\hline $\mathrm{w}_{11}$ & $\mathrm{~W}_{12}$ & $\mathrm{w}_{21}$ & $\mathrm{~W}_{22}$ & $\mathrm{w}_{23}$ & $\mathrm{w}_{31}$ & $\mathrm{~W}_{32}$ & $\mathrm{w}_{41}$ \\
\hline 0.107 & 0.037 & 0.070 & 0.149 & 0.149 & 0.065 & 0,114 & 0,309 \\
\hline \multicolumn{4}{|c|}{ Strengthening } & \multicolumn{2}{|c|}{ Weakening } & \multicolumn{2}{|c|}{ Antagonism } \\
\hline $\mathrm{g}_{\mathrm{T} 1 .} \mathrm{g}_{\mathrm{T} 2}$ & $\mathrm{~g}_{\mathrm{T} 1 .} \mathrm{g}_{\mathrm{E} 3}$ & $\begin{array}{c}\mathrm{g}_{\mathrm{E} 2 .} \\
\mathrm{g}_{\mathrm{S} 1}\end{array}$ & $\mathrm{~g}_{\mathrm{R} 1 .} \mathrm{g}_{\mathrm{R} 2}$ & \multicolumn{2}{|c|}{$\mathrm{g}_{\mathrm{E} 2 .} \mathrm{g}_{\mathrm{E} 3}$} & \multicolumn{2}{|c|}{$\mathrm{g}_{\mathrm{E} 2 .} \mathrm{g}_{\mathrm{R} 3}$} \\
\hline $\mathrm{W}_{11 \_12}$ & $\mathrm{~W}_{11 \_23}$ & $\mathrm{~W}_{22 \_} 41$ & $\mathrm{~W}_{31 \_32}$ & \multicolumn{2}{|c|}{$\mathrm{W}_{22} \_23$} & \multicolumn{2}{|c|}{$\mathrm{W}_{22}{ }_{2} 32$} \\
\hline 0.099 & 0.077 & 0.179 & 0.090 & & & & 72 \\
\hline & & hird mo & t frequen & partate & teda & & \\
\hline & & & $\mathrm{G}_{\mathrm{E}}$ & & & & Gs \\
\hline & & & 0.445 & & & & 0.355 \\
\hline $\mathrm{g}_{\mathrm{T} 1}$ & $\mathrm{~g}_{\mathrm{T} 2}$ & $\mathrm{~g}_{\mathrm{E} 1}$ & $\mathrm{~g}_{\mathrm{E} 2}$ & $\mathrm{~g}_{\mathrm{E} 3}$ & $\mathrm{~g}_{\mathrm{R} 1}$ & $\mathrm{~g}_{\mathrm{R} 2}$ & $\mathrm{~g}_{\mathrm{S} 1}$ \\
\hline $\mathrm{w}_{11}$ & $\mathrm{w}_{12}$ & $\mathrm{w}_{21}$ & $\mathrm{w}_{22}$ & $\mathrm{w}_{23}$ & $w_{31}$ & $\mathrm{w}_{32}$ & $\mathrm{~W}_{41}$ \\
\hline 0.108 & 0.037 & 0.070 & 0.147 & 0.147 & 0.065 & 0,117 & 0,308 \\
\hline & Strengt & ening & & Weal & ning & Ant & onism \\
\hline $\mathrm{g}_{\mathrm{T} 1} \cdot \mathrm{g}_{\mathrm{T} 2}$ & $\mathrm{~g}_{\mathrm{T} 1 .} \mathrm{g}_{\mathrm{E} 3}$ & $\begin{array}{c}\mathrm{g}_{\mathrm{E} 2} . \\
\mathrm{g}_{\mathrm{S} 1}\end{array}$ & $\mathrm{~g}_{\mathrm{R} 1 .} \mathrm{g}_{\mathrm{R} 2}$ & $\mathrm{~g}_{\mathrm{E} 2}$ & & & $g_{\mathrm{R} 3}$ \\
\hline $\mathrm{W}_{11 \_12}$ & $\mathrm{~W}_{11 \_23}$ & $\mathrm{~W}_{22 \_41}$ & $\mathrm{~W}_{31 \_32}$ & & & & \\
\hline 0.045 & 0.033 & 0.092 & 0.021 & & & & \\
\hline
\end{tabular}

The DMs appeared to be satisfied with the results, since the most frequent partial pre-order reflects their preferences. In their opinion, the winning alternative would be useful in helping the city and the Piedmont region meet their goal of creating a tourist hub.

\section{Conclusions}


In this paper we applied a recently introduced MCDA methodology, the robust and hierarchical ELECTRE III method, introducing a specific improvement of the procedure to elicit weights of criteria, named SRF- II method, in order to give robust recommendations about the problem at hand.

We simulated the decision-making process by using the preference information provided by two consultants of the Politecnico di Torino project team acting as DMs. This information was used in the methodology to produce preference rankings for six different requalification projects for an iconic building: the Stock Exchange.

The paper's aim was to test the methodology's applicability to architecture. This type of application involves quantifying purely qualitative aesthetic and spatial aspects in numerical variables. Accordingly, the methodology allows the use of heterogeneous units of measure, whereby the aesthetic and qualitative aspects typical of architecture can be appropriately expressed. ELECTRE III takes the uncertainty and imprecision that can occur in defining the family of criteria into account by defining preference and indifference thresholds. Moreover, the preference information expressed by the DMs through the new robust SRF-II method leads to a large set of compatible vectors of weights and interaction coefficients. All these possibilities are taken into account through the use of the SMAA methodology, which provides robust conclusions on the final rankings of the alternatives by means of a large number of simulations with different compatible vectors of parameters. It provides preference, indifference and incomparability relations between alternatives not only at the comprehensive level but also considering a particular macro-criterion.

We asked our DMs to express a classification of the criteria individually and then jointly, in order to provide them with three different results based on different preference information. Though the proposed methodology can represent the complexity of a decision-making process through the interactions between the criteria, this aspect could also be considered critical: the information required to the DMs can be very specific in different areas, and given that the DMs are not required to be thoroughly versed in all aspects of the problem, they could have some trouble in expressing the preferential information. In any case, considering interaction between criteria is a further option provided by the method, but DMs are not compelled to use this option. DMs can take interactions of criteria into account if they feel that interactions are relevant for the decision problem and if they feel able to supply reliable preference information. Otherwise, the method can be successfully applied without taking any interaction between criteria into account. Another critical point is that many meetings with the DMs are needed, which may limit the method's applicability (but it must be admitted that this is a common problem with these types of approach). Of course, one must accept that applying a systematic decision aiding methodology calls for a certain commitment on the part of the DMs, as otherwise the results would be inaccurate, misleading, shallow and entirely unreliable. Accordingly, we introduced an innovation in the procedure to elicit weights of criteria. More precisely, we considered the SRF deck of cards method, focusing our attention on the $\mathrm{z}$ value, which is the ratio of the weight of the most important criteria to the weight of the least important criteria. This is a rather complex and difficult information for the DM, as it is very different from the other types of information that the DM is required to provide, as it is a number of blank cards between successive levels of cards representing criteria of the same importance. The higher the number of blank cards, the greater the difference between weights of criteria in the contiguous levels. Compared to this type of information, the $\mathrm{z}$ value requires a quite different kind of thinking and this, in general, can cause confusion and perplexity for the DM. To handle this problem, we proposed the SRF-II method, where the $\mathrm{z}$ value is replaced with information that is more similar in kind to the other information required in the elicitation procedure. This is the number of blank cards between the card corresponding to least important criterion and the "zero criterion". Our case study proved that the DM is comfortable in providing this information, finding it to be clear and understandable. The elicitation procedure thus requires significantly less cognitive effort and produces more robust, reliable results. Consequently, in addition to being of interest for the specific decision problem we considered in this paper, the SRF-II method proves in general to be a valuable improvement for all applications. As further directions of research, we plan to perform some experiments to compare the SRF and SRF-II methods both with respect to the ease of applying them and to the capacity of the results obtained by their application to correctly represent the preferences of the DMs.

Though the model presented here has certain limitations, as it was applied to a fairly small set of alternatives and it was not possible to interface with the DMs in the real decision-making process, it nevertheless demonstrates that the methodology is a valuable tool for aiding architectural choices in real-world decision problems, where the use of architectural criteria is a challenge that we will continue to investigate in future research.

\section{Appendix}

With respect to the technical macro-criterion, only one partial pre-order (shown in Fig. 10) for the projects at hand is obtained considering the barycenter of the set of parameter vectors given in Table 9. 
Table 9 Barycenter of the set of parameter vectors with respect to the technical macro-criterion

\begin{tabular}{|c|c|c|c|c|c|c|c|}
\hline \multicolumn{2}{|c|}{$\mathrm{G}_{\mathrm{T}}$} & \multicolumn{3}{|c|}{$\mathrm{G}_{\mathrm{E}}$} & \multicolumn{2}{|c|}{$\mathrm{G}_{\mathrm{R}}$} & Gs \\
\hline $\mathrm{g}_{\mathrm{T} 1}$ & $\mathrm{~g}_{\mathrm{T} 2}$ & $\mathrm{~g}_{\mathrm{E} 1}$ & $\mathrm{~g}_{\mathrm{E} 2}$ & $\mathrm{~g}_{\mathrm{E} 3}$ & $\mathrm{~g}_{\mathrm{R} 1}$ & $\mathrm{~g}_{\mathrm{R} 2}$ & $\mathrm{~g}_{\mathrm{S} 1}$ \\
\hline $\mathrm{W}_{11}$ & $\mathrm{~W}_{12}$ & $\mathrm{~W}_{21}$ & $\mathrm{~W}_{22}$ & $\mathrm{~W}_{23}$ & $\mathrm{w}_{31}$ & $\mathrm{w}_{32}$ & $\mathrm{~W}_{41}$ \\
\hline 0.108 & 0.03 & 0.070 & 0.147 & 0.147 & 0.067 & 0,115 & 0,308 \\
\hline \multicolumn{4}{|c|}{ Strengthening } & \multicolumn{2}{|c|}{ Weakening } & \multicolumn{2}{|c|}{ Antagonism } \\
\hline $\mathrm{g}_{\mathrm{T} 1 .} \mathrm{g}_{\mathrm{T} 2}$ & $\mathrm{~g}_{\mathrm{T} 1 .} \mathrm{g}_{\mathrm{E} 3}$ & $\mathrm{~g}_{\mathrm{E} 2 .} \mathrm{g}_{\mathrm{S} 1}$ & $\mathrm{~g}_{\mathrm{R} 1 .} \mathrm{g}_{\mathrm{R} 2}$ & \multicolumn{2}{|c|}{$\mathrm{g}_{\mathrm{E} 2 .} \mathrm{g}_{\mathrm{E} 3}$} & \multicolumn{2}{|c|}{$\mathrm{g}_{\mathrm{E} 2 .} \mathrm{g}_{\mathrm{R} 3}$} \\
\hline $\mathrm{W}_{11} 12$ & $\mathrm{~W}_{11 \_23}$ & $\mathrm{~W}_{22}{ }_{41}$ & $\mathrm{~W}_{31 \_32}$ & \multicolumn{2}{|c|}{$\mathrm{W}_{22 \_23}$} & \multicolumn{2}{|c|}{$\mathrm{W}_{22 \_32}$} \\
\hline 0.111 & 0.148 & 0.277 & 0.070 & \multicolumn{2}{|c|}{-0.033} & \multicolumn{2}{|c|}{0.043} \\
\hline
\end{tabular}

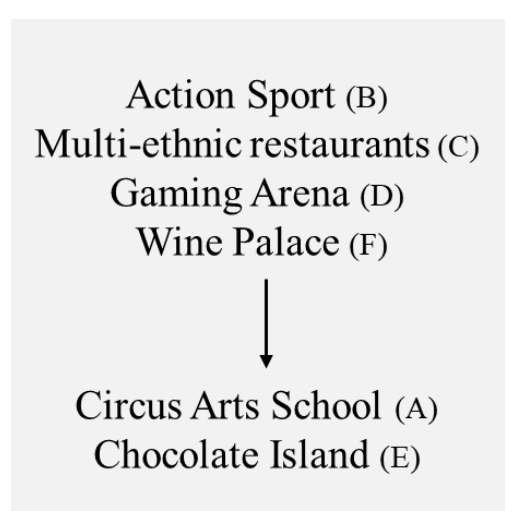

Fig. 10 Unique partial pre-order of the projects with respect to the technical macro-criterion

This ranking is supported by the frequencies of preference, indifference and incompatibility shown in Table 10, Table 11 and Table 12, respectively.

Table 10 Frequency of indifference

\begin{tabular}{|l|c|c|c|c|c|c|}
\hline & $\boldsymbol{A}$ & $\boldsymbol{B}$ & $\boldsymbol{C}$ & $\boldsymbol{D}$ & $\boldsymbol{E}$ & $\boldsymbol{F}$ \\
\hline $\boldsymbol{A}$ & 0 & 0 & 0 & 0 & 100 & 0 \\
\hline $\boldsymbol{B}$ & 0 & 0 & 100 & 100 & 0 & 100 \\
\hline $\boldsymbol{C}$ & 0 & 100 & 0 & 100 & 0 & 100 \\
\hline $\boldsymbol{D}$ & 0 & 100 & 100 & 0 & 0 & 100 \\
\hline $\boldsymbol{E}$ & 100 & 0 & 0 & 0 & 0 & 0 \\
\hline $\boldsymbol{F}$ & 0 & 100 & 100 & 100 & 0 & 0 \\
\hline
\end{tabular}

Table 11 Frequency of preference

\begin{tabular}{|l|c|c|c|c|c|c|}
\hline & $\boldsymbol{A}$ & $\boldsymbol{B}$ & $\boldsymbol{C}$ & $\boldsymbol{D}$ & $\boldsymbol{E}$ & $\boldsymbol{F}$ \\
\hline $\boldsymbol{A}$ & 0 & 0 & 0 & 0 & 0 & 0 \\
\hline $\boldsymbol{B}$ & 100 & 0 & 0 & 0 & 100 & 0 \\
\hline $\boldsymbol{C}$ & 100 & 0 & 0 & 0 & 100 & 0 \\
\hline $\boldsymbol{D}$ & 100 & 0 & 0 & 0 & 100 & 0 \\
\hline $\boldsymbol{E}$ & 0 & 0 & 0 & 0 & 0 & 0 \\
\hline $\boldsymbol{F}$ & 100 & 0 & 0 & 0 & 100 & 0 \\
\hline
\end{tabular}

Table 12 Frequency of incompatibility

\begin{tabular}{|l|c|c|c|c|c|c|}
\hline & $\boldsymbol{A}$ & $\boldsymbol{B}$ & $\boldsymbol{C}$ & $\boldsymbol{D}$ & $\boldsymbol{E}$ & $\boldsymbol{F}$ \\
\hline $\boldsymbol{A}$ & 0 & 0 & 0 & 0 & 0 & 0 \\
\hline $\boldsymbol{B}$ & 0 & 0 & 0 & 0 & 0 & 0 \\
\hline $\boldsymbol{C}$ & 0 & 0 & 0 & 0 & 0 & 0 \\
\hline
\end{tabular}




\begin{tabular}{|l|l|l|l|l|l|l|}
\hline $\boldsymbol{D}$ & 0 & 0 & 0 & 0 & 0 & 0 \\
\hline $\boldsymbol{E}$ & 0 & 0 & 0 & 0 & 0 & 0 \\
\hline $\boldsymbol{F}$ & 0 & 0 & 0 & 0 & 0 & 0 \\
\hline
\end{tabular}

With respect to the economic macro-criterion, three different partial pre-orders (shown in Fig. 11, Fig. 12 and Fig. 13, respectively) can be obtained. The barycenters of the set of parameter vectors giving these partial pre-orders are shown in Table 13. According to the barycenter of the weights (Table 13), the most frequent partial pre-order at secondary level of the hierarchy with respect to the economic macro-criteria is shown in Fig. 11. This partial pre-order occurred in $50.35 \%$ of cases, and was followed by the second partial pre-order with a frequency of $49.38 \%$ (Fig. 12) and the third with a frequency of $0.27 \%$ (Fig. 13).

Table 13 Barycenters of the set of parameter vectors on economic macro-criterion

\begin{tabular}{|c|c|c|c|c|c|c|c|}
\hline \multicolumn{8}{|c|}{ Most frequent partial pre-order } \\
\hline \multicolumn{2}{|c|}{$\mathrm{G}_{\mathrm{T}}$} & \multicolumn{3}{|c|}{$\mathrm{G}_{\mathrm{E}}$} & \multicolumn{2}{|c|}{$\mathrm{G}_{\mathrm{R}}$} & \multirow{2}{*}{$\begin{array}{c}\text { Gs } \\
\mathrm{g}_{\mathrm{S} 1}\end{array}$} \\
\hline $\mathrm{g}_{\mathrm{T} 1}$ & $\mathrm{~g}_{\mathrm{T} 2}$ & $\mathrm{~g}_{\mathrm{E} 1}$ & $\mathrm{~g}_{\mathrm{E} 2}$ & $\mathrm{~g}_{\mathrm{E} 3}$ & $\mathrm{~g}_{\mathrm{R} 1}$ & $\mathrm{~g}_{\mathrm{R} 2}$ & \\
\hline $\mathrm{w}_{11}$ & $\mathrm{w}_{12}$ & $\mathrm{w}_{21}$ & $\mathrm{w}_{22}$ & $\mathrm{w}_{23}$ & $\mathrm{w}_{31}$ & $\mathrm{w}_{32}$ & $\mathrm{~W}_{41}$ \\
\hline 0.109 & 0.038 & 0.072 & 0.145 & 0.145 & 0.067 & 0.116 & 0.308 \\
\hline \multicolumn{4}{|c|}{ Strengthening } & \multicolumn{2}{|c|}{ Weakening } & \multicolumn{2}{|c|}{ Antagonism } \\
\hline $\begin{array}{l}\mathrm{g}_{\mathrm{T} 1} \\
\mathrm{~g}_{\mathrm{T} 2} \\
\end{array}$ & $\begin{array}{l}\mathrm{g}_{\mathrm{T} 1} \\
\mathrm{~g}_{\mathrm{E} 3} \\
\end{array}$ & $\begin{array}{c}\mathrm{g}_{\mathrm{E} 2 .} \\
\mathrm{g}_{\mathrm{S} 1}\end{array}$ & $\mathrm{~g}_{\mathrm{R} 1 .} \mathrm{g}_{\mathrm{R} 2}$ & \multicolumn{2}{|c|}{$\mathrm{g}_{\mathrm{E} 2 .} \mathrm{g}_{\mathrm{E} 3}$} & \multicolumn{2}{|c|}{$\mathrm{g}_{\mathrm{E} 2 .} \mathrm{g}_{\mathrm{R} 3}$} \\
\hline $\mathrm{W}_{11 \_12}$ & $\mathrm{~W}_{11} \_23$ & W22_41 & W31_32 & \multicolumn{2}{|c|}{$\mathrm{W}_{22} \_23$} & \multicolumn{2}{|c|}{$\mathrm{W}_{22}$-32 } \\
\hline 0.062 & 0.113 & 0.227 & 0.049 & \multicolumn{2}{|c|}{-0.035} & \multicolumn{2}{|c|}{0.050} \\
\hline \multicolumn{8}{|c|}{ Second most frequent partial pre-order } \\
\hline \multicolumn{2}{|c|}{$\mathrm{G}_{\mathrm{T}}$} & \multicolumn{3}{|c|}{$\mathrm{G}_{\mathrm{E}}$} & \multicolumn{2}{|c|}{$\mathrm{G}_{\mathrm{R}}$} & Gs \\
\hline $\mathrm{g}_{\mathrm{T} 1}$ & $\mathrm{~g}_{\mathrm{T} 2}$ & $\mathrm{~g}_{\mathrm{E} 1}$ & $\mathrm{~g}_{\mathrm{E} 2}$ & $\mathrm{~g}_{\mathrm{E} 3}$ & $\mathrm{~g}_{\mathrm{R} 1}$ & $\mathrm{~g}_{\mathrm{R} 2}$ & $\mathrm{~g}_{\mathrm{S} 1}$ \\
\hline $\mathrm{w}_{11}$ & $\mathrm{w}_{12}$ & $\mathrm{w}_{21}$ & $\mathrm{w}_{22}$ & $\mathrm{w}_{23}$ & $\mathrm{w}_{31}$ & $\mathrm{w}_{32}$ & $\mathrm{w}_{41}$ \\
\hline 0.108 & 0.037 & 0.067 & 0.149 & 0.149 & 0.067 & 0.115 & 0.308 \\
\hline \multicolumn{4}{|c|}{ Strengthening } & \multicolumn{2}{|c|}{ Weakening } & \multicolumn{2}{|c|}{ Antagonism } \\
\hline $\begin{array}{l}\mathrm{g}_{\mathrm{T} 1}, \\
\mathrm{~g}_{\mathrm{T} 2}\end{array}$ & $\begin{array}{l}\mathrm{g}_{\mathrm{T} 1,} \\
\mathrm{~g}_{\mathrm{E} 3}\end{array}$ & $\begin{array}{l}\mathrm{g}_{\mathrm{E} 2} \\
\mathrm{~g}_{\mathrm{S} 1}\end{array}$ & $\mathrm{~g}_{\mathrm{R} 1, \mathrm{~g}_{\mathrm{R} 2}}$ & \multicolumn{2}{|c|}{$\mathrm{g}_{\mathrm{E} 2,} \mathrm{~g}_{\mathrm{E} 3}$} & \multicolumn{2}{|c|}{$\mathrm{g}_{\mathrm{E} 2,} \mathrm{~g}_{\mathrm{R} 3}$} \\
\hline $\mathrm{W}_{11}{ }_{-} 12$ & W11_23 & $\mathrm{W}_{22}{ }_{-41}$ & $\mathrm{~W}_{31 \_32}$ & \multicolumn{2}{|c|}{$\mathrm{W}_{22} 23$} & \multicolumn{2}{|c|}{$\mathrm{W}_{22}{ }_{-32}$} \\
\hline 0.159 & 0.184 & 0.329 & 0.092 & \multicolumn{2}{|c|}{-0.032} & \multicolumn{2}{|c|}{0.037} \\
\hline \multicolumn{8}{|c|}{ Third most frequent partial pre-order } \\
\hline \multicolumn{2}{|c|}{$\mathrm{G}_{\mathrm{T}}$} & \multicolumn{3}{|c|}{$\mathrm{G}_{\mathrm{E}}$} & \multicolumn{2}{|c|}{$\mathrm{G}_{\mathrm{R}}$} & Gs \\
\hline $\mathrm{g}_{\mathrm{T} 1}$ & $\mathrm{~g}_{\mathrm{T} 2}$ & $\mathrm{~g}_{\mathrm{E} 1}$ & $\mathrm{~g}_{\mathrm{E} 2}$ & $\mathrm{~g}_{\mathrm{E} 3}$ & $\mathrm{~g}_{\mathrm{R} 1}$ & $\mathrm{~g}_{\mathrm{R} 2}$ & $\mathrm{~g}_{\mathrm{S} 1}$ \\
\hline $\mathrm{w}_{11}$ & $\mathrm{w}_{12}$ & $\mathrm{w}_{21}$ & $\mathrm{w}_{22}$ & $\mathrm{w}_{23}$ & $\mathrm{w}_{31}$ & $\mathrm{w}_{32}$ & $\mathrm{~W}_{41}$ \\
\hline 0.109 & 0.035 & 0.080 & 0.142 & 0.142 & 0.067 & 0,113 & 0,312 \\
\hline \multicolumn{4}{|c|}{ Strengthening } & Weak & ning & Antag & nism \\
\hline $\begin{array}{l}\mathrm{g}_{\mathrm{T} 1} . \\
\mathrm{g}_{\mathrm{T} 2}\end{array}$ & $\begin{array}{l}\mathrm{g}_{\mathrm{T} 1} \\
\mathrm{~g}_{\mathrm{E} 3} \\
\end{array}$ & $\begin{array}{l}\mathrm{g}_{\mathrm{E} 2} \\
\mathrm{~g}_{\mathrm{S} 1} \\
\end{array}$ & $\mathrm{~g}_{\mathrm{R} 1 .} \mathrm{g}_{\mathrm{R} 2}$ & $\mathrm{~g}_{\mathrm{E} 2}$ & $\mathrm{~g}_{\mathrm{E} 3}$ & $\mathrm{~g}_{\mathrm{E} 2}$ & $g_{\mathrm{R} 3}$ \\
\hline $\mathrm{W}_{11}{ }_{-} 12$ & $\mathrm{~W}_{11 \_23}$ & $\mathrm{~W}_{22}$-41 & $\mathrm{W}_{31 \_32}$ & & & & \\
\hline 0.014 & 0.055 & 0.164 & 0.045 & -0 . & & & \\
\hline
\end{tabular}




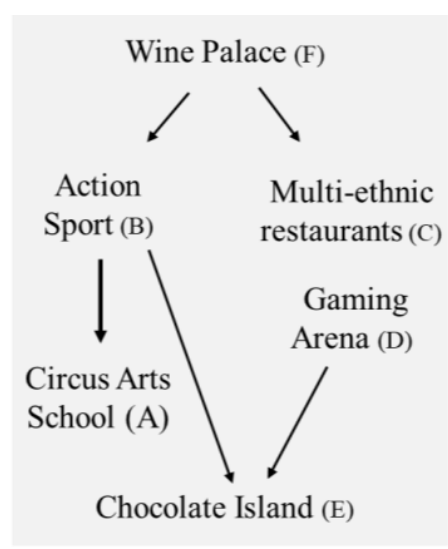

Fig. 11 Most frequent partial preorder $(50.35 \%)$ with respect to the economic macro-criterion

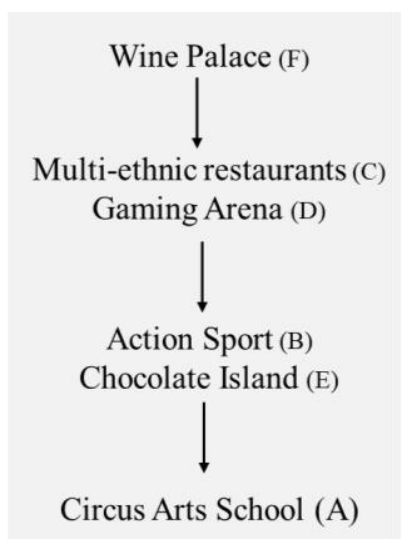

Fig. 12 Second most frequent partial pre-order $(49.38 \%)$ with respect to the economic macrocriterion

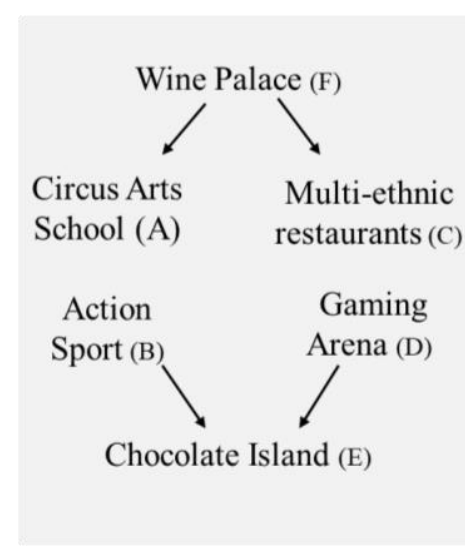

Fig. 13 Third most frequent partial pre-order $(0.27 \%)$ with respect to the economic macrocriterion

The information gathered by these rankings is enriched by the frequencies of preference, indifference and incompatibility shown in Table 14, Table 15, and Table 16, respectively.

Table 14 Frequency of indifference

\begin{tabular}{|l|c|c|c|c|c|c|}
\hline & $\boldsymbol{A}$ & $\boldsymbol{B}$ & $\boldsymbol{C}$ & $\boldsymbol{D}$ & $\boldsymbol{E}$ & $\boldsymbol{F}$ \\
\hline $\boldsymbol{A}$ & 0 & 0.27 & 0 & 0 & 0 & 0 \\
\hline $\boldsymbol{B}$ & 0.27 & 0 & 0 & 0 & 49.38 & 0 \\
\hline $\boldsymbol{C}$ & 0 & 0 & 0 & 100 & 0 & 0 \\
\hline $\boldsymbol{D}$ & 0 & 0 & 100 & 0 & 0 & 0 \\
\hline $\boldsymbol{E}$ & 0 & 49.38 & 0 & 0 & 0 & 0 \\
\hline $\boldsymbol{F}$ & 0 & 0 & 0 & 0 & 0 & 0 \\
\hline
\end{tabular}

Table 15 Frequency of preference

\begin{tabular}{|l|c|c|c|c|c|c|}
\hline & $\boldsymbol{A}$ & $\boldsymbol{B}$ & $\boldsymbol{C}$ & $\boldsymbol{D}$ & $\boldsymbol{E}$ & $\boldsymbol{F}$ \\
\hline $\boldsymbol{A}$ & 0 & 0 & 0 & 0 & 0,27 & 0 \\
\hline $\boldsymbol{B}$ & 99.73 & 0 & 0 & 0 & 50.62 & 0 \\
\hline $\boldsymbol{C}$ & 49.38 & 49.38 & 0 & 0 & 100 & 0 \\
\hline $\boldsymbol{D}$ & 49.38 & 49.38 & 0 & 0 & 100 & 0 \\
\hline $\boldsymbol{E}$ & 49.38 & 0 & 0 & 0 & 0 & 0 \\
\hline $\boldsymbol{F}$ & 100 & 100 & 100 & 100 & 100 & 0 \\
\hline
\end{tabular}

Table 16 Frequency of incompatibility

\begin{tabular}{|l|c|c|c|c|c|c|}
\hline & $\boldsymbol{A}$ & $\boldsymbol{B}$ & $\boldsymbol{C}$ & $\boldsymbol{D}$ & $\boldsymbol{E}$ & $\boldsymbol{F}$ \\
\hline $\boldsymbol{A}$ & 0 & 0 & 50.62 & 50.62 & 50.35 & 0 \\
\hline $\boldsymbol{B}$ & 0 & 0 & 50.62 & 50.62 & 0 & 0 \\
\hline $\boldsymbol{C}$ & 50.62 & 50.62 & 0 & 0 & 0 & 0 \\
\hline $\boldsymbol{D}$ & 50.62 & 50.62 & 0 & 0 & 0 & 0 \\
\hline $\boldsymbol{E}$ & 50.35 & 0 & 0 & 0 & 0 & 0 \\
\hline $\boldsymbol{F}$ & 0 & 0 & 0 & 0 & 0 & 0 \\
\hline
\end{tabular}

With respect to the reuse macro-criterion, only one partial pre-order can be obtained (Fig. 14). The barycenter of the set of parameter vectors giving this partial pre-order is shown in Table 17.

Table 17 Barycenter of the set of parameter vectors on reuse macro-criterion

\begin{tabular}{|l|l|l|l|}
\hline $\mathrm{G}_{\mathrm{T}}$ & $\mathrm{G}_{\mathrm{E}}$ & $\mathrm{G}_{\mathrm{R}}$ & $\mathrm{Gs}$ \\
\hline
\end{tabular}




\begin{tabular}{|c|c|c|c|c|c|c|c|}
\hline $\mathrm{g}_{\mathrm{T} 1}$ & $\mathrm{~g}_{\mathrm{T} 2}$ & $\mathrm{~g}_{\mathrm{E} 1}$ & $\mathrm{~g}_{\mathrm{E} 2}$ & $\mathrm{~g}_{\mathrm{E} 3}$ & $\mathrm{~g}_{\mathrm{R} 1}$ & $\mathrm{~g}_{\mathrm{R} 2}$ & $\mathrm{~g}_{\mathrm{S} 1}$ \\
\hline $\mathrm{w}_{11}$ & $\mathrm{w}_{12}$ & $\mathrm{w}_{21}$ & $\mathrm{w}_{22}$ & $\mathrm{w}_{23}$ & $\mathrm{w}_{31}$ & $\mathrm{w}_{32}$ & $\mathrm{w}_{41}$ \\
\hline 0.108 & 0.037 & 0.070 & 0.147 & 0.147 & 0.067 & 0,116 & 0,308 \\
\hline \multicolumn{7}{|c|}{ Strengthening } \\
\hline $\begin{array}{c}\mathrm{g}_{\mathrm{T} 1 .} \\
\mathrm{g}_{\mathrm{T} 2}\end{array}$ & $\begin{array}{c}\mathrm{g}_{\mathrm{T} 1 .} \\
\mathrm{g}_{\mathrm{E} 3}\end{array}$ & $\begin{array}{c}\mathrm{g}_{\mathrm{E} 2 .} \\
\mathrm{g}_{\mathrm{S} 1}\end{array}$ & $\mathrm{~g}_{\mathrm{R} 1 .} \mathrm{g}_{\mathrm{R} 2}$ & $\mathrm{~g}_{\mathrm{E} 2 .} \mathrm{g}_{\mathrm{E} 3}$ & $\mathrm{~g}_{\mathrm{E} 2 .} \mathrm{g}_{\mathrm{R} 3}$ \\
\hline $\mathrm{w}_{11} 12$ & $\mathrm{w} 11 \_23$ & $\mathrm{w}_{22} 41$ & $\mathrm{w}_{1} \_32$ & $\mathrm{w}_{22} 23$ & $\mathrm{w}_{22} 32$ \\
\hline 0.111 & 0.148 & 0.277 & 0.070 & -0.033 & 0.043 \\
\hline
\end{tabular}

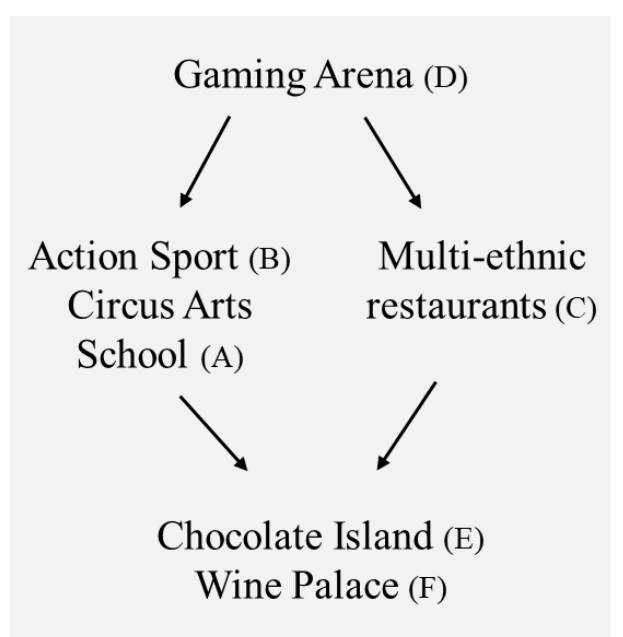

Fig. 14 Unique partial pre-order with respect to the reuse macro-criterion

This ranking is supported by the frequencies of preference, indifference and incomparability shown in Table 18, Table 19 and Table 20, respectively.

Table 18 Frequency of indifference

\begin{tabular}{|l|c|c|c|c|c|c|}
\hline & $\boldsymbol{A}$ & $\boldsymbol{B}$ & $\boldsymbol{C}$ & $\boldsymbol{D}$ & $\boldsymbol{E}$ & $\boldsymbol{F}$ \\
\hline $\boldsymbol{A}$ & 0 & 100 & 0 & 0 & 0 & 0 \\
\hline $\boldsymbol{B}$ & 100 & 0 & 0 & 0 & 0 & 0 \\
\hline $\boldsymbol{C}$ & 0 & 0 & 0 & 0 & 0 & 0 \\
\hline $\boldsymbol{D}$ & 0 & 0 & 0 & 0 & 0 & 0 \\
\hline $\boldsymbol{E}$ & 0 & 0 & 0 & 0 & 0 & 100 \\
\hline $\boldsymbol{F}$ & 0 & 0 & 0 & 0 & 100 & 0 \\
\hline
\end{tabular}

Table 19 Frequency of preference

\begin{tabular}{|l|c|c|c|c|c|c|}
\hline & $\boldsymbol{A}$ & $\boldsymbol{B}$ & $\boldsymbol{C}$ & $\boldsymbol{D}$ & $\boldsymbol{E}$ & $\boldsymbol{F}$ \\
\hline $\boldsymbol{A}$ & 0 & 0 & 0 & 0 & 100 & 100 \\
\hline $\boldsymbol{B}$ & 0 & 0 & 0 & 0 & 100 & 100 \\
\hline $\boldsymbol{C}$ & 0 & 0 & 0 & 0 & 100 & 100 \\
\hline $\boldsymbol{D}$ & 100 & 100 & 100 & 0 & 100 & 100 \\
\hline $\boldsymbol{E}$ & 0 & 0 & 0 & 0 & 0 & 0 \\
\hline $\boldsymbol{F}$ & 0 & 0 & 0 & 0 & 0 & 0 \\
\hline
\end{tabular}

Table 20 Frequency of incomparability

\begin{tabular}{|l|c|c|c|c|c|c|}
\hline & $\boldsymbol{A}$ & $\boldsymbol{B}$ & $\boldsymbol{C}$ & $\boldsymbol{D}$ & $\boldsymbol{E}$ & $\boldsymbol{F}$ \\
\hline $\boldsymbol{A}$ & 0 & 0 & 100 & 0 & 0 & 0 \\
\hline $\boldsymbol{B}$ & 0 & 0 & 100 & 0 & 0 & 0 \\
\hline $\boldsymbol{C}$ & 100 & 100 & 0 & 0 & 0 & 0 \\
\hline
\end{tabular}




\begin{tabular}{|l|l|l|l|l|l|l|}
\hline $\boldsymbol{D}$ & 0 & 0 & 0 & 0 & 0 & 0 \\
\hline $\boldsymbol{E}$ & 0 & 0 & 0 & 0 & 0 & 0 \\
\hline $\boldsymbol{F}$ & 0 & 0 & 0 & 0 & 0 & 0 \\
\hline
\end{tabular}

A unique partial pre-order of the projects at hand can also be obtained for the social macro-criterion (Fig. 15). The barycenter of the set of parameter vectors giving this partial pre-order is shown in Table 21.

Table 21 Barycenter of the set of parameter vectors

\begin{tabular}{|c|c|c|c|c|c|c|c|}
\hline \multicolumn{2}{|c|}{$\mathrm{G}_{\mathrm{T}}$} & \multicolumn{3}{|c|}{$\mathrm{G}_{\mathrm{E}}$} & \multicolumn{2}{|c|}{$\mathrm{G}_{\mathrm{R}}$} & \multirow{2}{*}{$\frac{\text { Gs }}{\mathrm{g}_{\mathrm{S} 1}}$} \\
\hline $\mathrm{g}_{\mathrm{T} 1}$ & $\mathrm{~g}_{\mathrm{T} 2}$ & $\mathrm{~g}_{\mathrm{E} 1}$ & $g_{\mathrm{E} 2}$ & $\mathrm{~g}_{\mathrm{E} 3}$ & $\mathrm{~g}_{\mathrm{R} 1}$ & $\mathrm{~g}_{\mathrm{R} 2}$ & \\
\hline $\mathrm{W}_{11}$ & $\mathrm{w}_{12}$ & $\mathrm{~W}_{21}$ & $\mathrm{~W}_{22}$ & $\mathrm{w}_{23}$ & $\mathrm{~W}_{31}$ & $\mathrm{~W}_{32}$ & $\mathrm{~W}_{41}$ \\
\hline 0.108 & 0.037 & 0.070 & 0.147 & 0.147 & 0.067 & 0.116 & 0.308 \\
\hline \multicolumn{4}{|c|}{ Strengthening } & \multicolumn{2}{|c|}{ Weakening } & \multicolumn{2}{|c|}{ Antagonism } \\
\hline $\begin{array}{l}\mathrm{g}_{\mathrm{T} 1 .} \\
\mathrm{g}_{\mathrm{T} 2}\end{array}$ & $\begin{array}{l}\mathrm{g}_{\mathrm{T} 1} \\
\mathrm{~g}_{\mathrm{E} 3} \\
\end{array}$ & $\begin{array}{c}\mathrm{g}_{\mathrm{E} 2 .} \\
\mathrm{g}_{\mathrm{S} 1}\end{array}$ & $\mathrm{~g}_{\mathrm{R} 1 .} \mathrm{g}_{\mathrm{R} 2}$ & \multicolumn{2}{|c|}{$\mathrm{g}_{\mathrm{E} 2 .} \mathrm{g}_{\mathrm{E} 3}$} & \multicolumn{2}{|c|}{$\mathrm{g}_{\mathrm{E} 2 .} \mathrm{g}_{\mathrm{R} 3}$} \\
\hline $\mathrm{W}_{11 \_12}$ & $\mathrm{~W}_{11 \_23}$ & $\mathrm{~W}_{22 \_41}$ & W31_32 & \multicolumn{2}{|c|}{$\mathrm{W}_{22 \_23}$} & \multicolumn{2}{|c|}{$\mathrm{W}_{22 \_32}$} \\
\hline 0.111 & 0.148 & 0.277 & 0.070 & \multicolumn{2}{|c|}{-0.033} & \multicolumn{2}{|c|}{0.043} \\
\hline
\end{tabular}

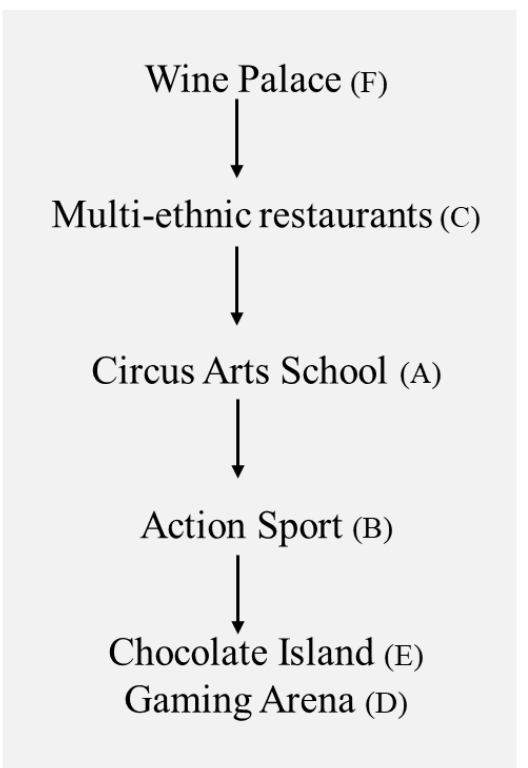

Fig. 15 Unique partial pre-order with respect to the reuse macro-criterion

This ranking is supported by the frequencies of preference, indifference and incomparability shown in Table 22, Table 23 and Table 24, respectively.

Table 22 Frequency of indifference

\begin{tabular}{|l|c|c|c|c|c|c|}
\hline & $\boldsymbol{A}$ & $\boldsymbol{B}$ & $\boldsymbol{C}$ & $\boldsymbol{D}$ & $\boldsymbol{E}$ & $\boldsymbol{F}$ \\
\hline $\boldsymbol{A}$ & 0 & 0 & 0 & 0 & 0 & 0 \\
\hline $\boldsymbol{B}$ & 0 & 0 & 0 & 0 & 0 & 0 \\
\hline $\boldsymbol{C}$ & 0 & 0 & 0 & 0 & 0 & 0 \\
\hline $\boldsymbol{D}$ & 0 & 0 & 0 & 0 & 100 & 0 \\
\hline $\boldsymbol{E}$ & 0 & 0 & 0 & 100 & 0 & 0 \\
\hline $\boldsymbol{F}$ & 0 & 0 & 0 & 0 & 0 & 0 \\
\hline
\end{tabular}

Table 23 Frequency of preference

\begin{tabular}{|c|c|c|c|c|c|c|}
\hline & $\boldsymbol{A}$ & $\boldsymbol{B}$ & $\boldsymbol{C}$ & $\boldsymbol{D}$ & $\boldsymbol{E}$ & $\boldsymbol{F}$ \\
\hline $\boldsymbol{A}$ & 0 & 100 & 0 & 100 & 100 & 0 \\
\hline
\end{tabular}




\begin{tabular}{|l|c|c|c|c|c|c|}
\hline $\boldsymbol{B}$ & 0 & 0 & 0 & 100 & 100 & 0 \\
\hline $\boldsymbol{C}$ & 100 & 100 & 0 & 100 & 100 & 0 \\
\hline $\boldsymbol{D}$ & 0 & 0 & 0 & 0 & 0 & 0 \\
\hline $\boldsymbol{E}$ & 0 & 0 & 0 & 0 & 0 & 0 \\
\hline $\boldsymbol{F}$ & 100 & 100 & 100 & 100 & 100 & 0 \\
\hline
\end{tabular}

Table 24 Frequency of incompatibility

\begin{tabular}{|l|c|c|c|c|c|c|}
\hline & $\boldsymbol{A}$ & $\boldsymbol{B}$ & $\boldsymbol{C}$ & $\boldsymbol{D}$ & $\boldsymbol{E}$ & $\boldsymbol{F}$ \\
\hline $\boldsymbol{A}$ & 0 & 0 & 0 & 0 & 0 & 0 \\
\hline $\boldsymbol{B}$ & 0 & 0 & 0 & 0 & 0 & 0 \\
\hline $\boldsymbol{C}$ & 0 & 0 & 0 & 0 & 0 & 0 \\
\hline $\boldsymbol{D}$ & 0 & 0 & 0 & 0 & 0 & 0 \\
\hline $\boldsymbol{E}$ & 0 & 0 & 0 & 0 & 0 & 0 \\
\hline $\boldsymbol{F}$ & 0 & 0 & 0 & 0 & 0 & 0 \\
\hline
\end{tabular}

Other data relating to the information provided by the two DMs separately along with the partial pre-orders and the frequencies of indifference, preference and incomparability at comprehensive level as well as on the four macro-criteria singularly can be downloaded by clicking on the following link: additional results.

\section{References}

Abastante, F. (2016). Multicriteria decision methodologies supporting decision processes: Empirical examples. GEAM- Geoingegneria Ambientale e Mineraria, 149, 5-18.

Abastante, F., Lami, I.M. (2013). An analytical model to evaluate a large-scale urban design competition. GEAM- Geoingegneria Ambientale e Mineraria, 139, 27-36.

Abastante, F., Corrente, S., Greco, S., Ishizaka, A., Lami, I.M. (2018). Choice architecture for architecture choices: Evaluating social housing initiatives putting together a parsimonious AHP methodology and the Choquet integral. Land Use Policy. 78, 748-762.

Abastante, F., Lami, I.M., Mecca, B. (2020). How to revitalise a historic district: A stakeholders-oriented assessment framework of adaptive reuse. In: Mondini G., Oppio A., Stanghellini S., Bottero M., Abastante F. (eds) Values and Functions for Future Cities. Green Energy and Technology. Springer, Cham, pp. 3-20.

Bottero, M., Ferretti, V., Figueira, J.R., Greco, S., Roy, B. (2015). Dealing with a multiple criteria environmental problem with interaction effects between criteria through an extension of the Electre III method. European Journal of Operational Research, 245(3), 837-850.

Bottero, M., D'Alpaos, C., Oppio, A. (2019). Ranking of adaptive reuse strategies for abandoned industrial heritage in vulnerable contexts: A multiple criteria decision aiding approach. Sustainability 11(3), 785.

Bullen P.A., Love P.E.D. (2011a). Factors influencing the adaptive re-use of buildings. Journal of Engineering, Design and Technology, 9(1), 32-46

Bullen P.A., Love P.E.D. (2011b). Adaptive reuse of heritage buildings. Structural Survey, 29(5), 411-421.

Camoletto, M., Ferri, G., Pedercini, C., Ingaramo, L., Sabatino, S., (2017). Social Housing e misurazione degli impatti sociali: passi avanti verso un toolkit comune. SIEV Società Italiana di Estimo e Valutazione, n.19.

Conejos, S., Yung, E.H.K., Chan, E.H.W. (2014). Evaluation of urban sustainability and adaptive reuse of built heritage areas: A case study on conservation in Hong Kong's CBD. Journal of Design Research, 12(4), 260-279.

Corrente, S., Figueira, J.R., Greco, S., Słowiński, R. (2017). A robust ranking method extending ELECTRE III to hierarchy of interacting criteria, imprecise weights and stochastic analysis. Omega 73, 1-17.

Corrente, S., Greco, S., Słowiński, R. (2012). Multiple Criteria Hierarchy Process in Robust Ordinal Regression. Decision Support Systems, 53(3), 660-674.

Corrente, S., Greco, S., Słowiński, R. (2013). Multiple Criteria Hierarchy Process with ELECTRE and PROMETHEE. Omega, 41, 820-846.

Corrente, S., Greco, S., Słowiński, R., (2016). Multiple Criteria Hierarchy Process for ELECTRE Tri methods. European Journal of Operational Research, 252(1), 191-203.

Costa, A.S., Lami, I.M., Greco, S., Figueira, J.R., Borbinha, J., (2019). A Multiple Criteria Approach Defining Cultural Adaptive Reuse of Abandoned Buildings. In: Huber S, Geiger M.J., Teixeira de Almeida A. (eds) Multiple Criteria Decision Making and Aiding: Cases on Models and Methods with Computer Implementations. International Series in Operations Research and Management Science, Springer, 274, 193-220.

Della Spina L. (2020). Adaptive sustainable reuse for cultural heritage: A multiple criteria decision aiding approach supporting urban development processes. Sustainability 12(4),1363. 
Dewiyana, E., Ibrahim, N., Hidayah, H.N. (2016). The Green Aspects of Adaptive Reuse of Hotel Penaga. Procedia - Social and Behavioral Sciences, 222, 631-643.

Douglas, J. (2006). Building Adaptation- Second Edition, Butterworth-Heinemann, Oxford.

Dyson, K., Matthews, J., Love, P.E.D. (2016). Critical success factors of adapting heritage buildings: an exploratory study. Built Environment Project and Asset Management 6(1), 44-57.

Elefante, C. (2007). The greenest building is... one that is already built. Forum Journal 2007, 21(4), 26. National Trust for Historic Preservation.

European Parliament (2016). Closing the loop. New circular economy package. Available at : https://www.europarl.europa.eu/RegData/etudes/BRIE/2016/573899/EPRS_BRI\%282016\%29573899_E N.pdf (Accessed on 29 June, 2020).

Figueira, J.R., Roy, B. (2002). Determining the weights of criteria in the ELECTRE type methods with a revised Simos' procedure. European Journal of Operational Research, 139, 317-326.

Figueira, J.R., Greco, S., Roy, B. (2009). ELECTRE methods with interaction between criteria: An extension of the concordance index. European Journal of Operational Research, 199(2), 478-495.

Figueira, J.R., Greco, S., Roy, B., Słowiński, R. (2013). An overview of ELECTRE methods and their recent extensions. Journal of Multi-Criteria Decision Analysis, 20, 61-85.

Fiorani, D., Loughlin, K., Musso, S.F. (2017). Conservation-Adaptation, keeping alive the spirit of the place, Adaptive reuse of heritage with symbolic value. EAAE Transactions on Architectural Education, 65, Hasselt, Belgium.

Foster, G. (2020). Circular economy strategies for adaptive reuse of cultural heritage buildings to reduce environmental impacts. Resources, Conservation and Recycling 152,104507.

Govindan, K., Jepsen, M.B. (2016). ELECTRE: A comprehensive literature review on methodologies and applications. European Journal of Operational Research, 250(1), 1-29.

Greco, S., Ehrgott, M. and Figueira, J.R. (2016). Multiple Criteria Decision Analysis: State of the Art Surveys. Springer-Verlag, New York.

Günçea, K., Mısırlısoya, D. (2015). Questioning the Adaptive Reuse of Industrial Heritage and Its Interventions in the Context of Sustainability. Sociology, 5(9), 718-727.

Keeney, R.,Raiffa, H. (1976). Decisions with multiple objectives: Preferences and value tradeoffs. J. Wiley, New York.

Kıran Çakır, H., Aydın, D., Arabulan, S. (2020). Adaptive reuse of open spaces in historical buildings. International Journal of Building Pathology and Adaptation. In press. https://doi.org/10.1108/IJBPA-042019-0034.

Kohler, N., Yang, W. (2007). "Long-term management of building stocks". Building Research and Information, 35(4), 351-362.

Lahdelma, R., Hokkanen, J., Salminen, P. (1998). SMAA-stochastic multiobjective acceptability analysis. European Journal of Operational Research, 106(1), 137-143.

Lami, I.M. (2020). Shapes, Rules and Values. In: Lami I.M., Abandoned Buildings in Contemporary Cities: smart conditions for actions. Smart Innovation, Systems and Technologies, vol 168, pp.149-162.

Martin, C., Lagret, M. (2005). La méthode multicritère ELECTRE III définitions, principe et exemple d'application à la gestion des eaux pluviales en milieu urbain, Bulletin des laboratoires des ponts et chaussées, N. 258-259, págs. 29-46.

Mousseau, V., Figueira, J.R., Dias, L., Gomes da Silva, C., Climaco, J. (2003). Resolving inconsistencies among constraints on the parameters of an MCDA model. European Journal of Operational Research, 147(1), 72-93.

Oppio, A., Bottero, M. (2017). Conflicting values in designing adaptive reuse for cultural heritage. A case study of social multicriteria evaluation. In: Gervasi O. et al. (eds) Computational Science and Its Applications - ICCSA 2017. ICCSA 2017. Lecture Notes in Computer Science, vol 10406. Springer, Cham, pp.607-623.

Oppio, A., Bottero, M., Ferretti, V. (2017). Designing adaptive reuse strategies for cultural heritage with choice experiments. In: Stanghellini S., Morano P., Bottero M., Oppio A. (eds) Appraisal: From Theory to Practice. Green Energy and Technology. Springer, Cham, pp. 303-315.

Papuzzi, A. (ed.), La borsa Valori di Torino. Il progetto, la sua storia, Allemandi \&C., Torino 2011.

Permata, D.D., Kuswandy, A.S., Riza, A.I., Sakti, P.F., Diana, T.I. (2020). The Centrum-Bandung: Adaptive Reuse at Heritage Building as Sustainable Architecture. IOP Conference Series: Earth and Environmental Science 409(1), 012036.

Plevoets, B., Van Cleempoel, K. (2013). Adaptive reuse as an emerging discipline: an historic survey. In Cairns G. (ed.), Reinventing architecture and interiors: a socio-political view on building adaptation (pp. 13-32). Libri Publishers, London.

Remøy, H.T., Van der Voordt, D.J.M. (2007). A new life: conversion of vacant office buildings into housing. Facilities 25(3-4), 88-103. 
Robiglio, M. (2016). The Adaptive Reuse Toolkit. How Cities Can Turn their Industrial Legacy into Infrastructure for Innovation and Growth, Urban and Regional Policy Paper n. 38, 5-38.

Roy, B. (1990). The outranking approach and the foundations of ELECTRE methods. Theory and Decision, $31,49-73$

Roy, B., Bouyssou, D. (1993). Aide Multicritère à la Décision: Méthodes et Cas. Paris: Economica.

Roy, B., Figueira, J.R., Almeida-Dias, J. (2014). Discriminating thresholds as a tool to cope with imperfect knowledge in multiple criteria decision aiding: Theoretical results and practical issues. Omega, 43, 9-20.

Simos, J. (1990). Evaluer l'impact sur l'environnement: Une approche originale par l'analyse multicritère et la négociation. Presses Polytechniques et Universitaires Romandes, Lausanne.

Smith, R.L. (1984). Efficient Monte Carlo procedures for generating points uniformly distributed over bounded regions. Operations Research, 32, 1296-1308.

Tervonen, T., Van Valkenhoed, G., Bastürk, N., Postmus, D. (2013). Hit-And-Run enables efficient weight generation for simulation-based multiple criteria decision analysis. European Journal of Operational Research, 224, 552-559.

Wakker, P.P. (1989). Additive representations of preferences: A new foundation of decision analysis. Springer. Young, E.H.K., Chan, E.H.W. (2012). Implementation challenges to the adaptive reuse of heritage buildings: Towards the goals of sustainable, low carbon cities. Habitat International, 36(3), 352-361. 